\title{
LA CORTE SUPREMA NORTEAMERICANA Y EL FEDERALISMO DEL BIENESTAR. A PROPÓSITO DEL JUICIO DE CONSTITUCIONALIDAD DE LA REFORMA SANITARIA
}

VÍCTOR J. VÁZQUEZ ALONSO 
SUMARIO

INTRODUCCIÓN. LA REFORMA SANITARIA: UN HITO LEGISLATIVO ANTE LA CORTE SUPREMA. 1. LOS FUNDAMENTOS (ECONÓMICOS) DE LA REFORMA 2. LA COMMERCE CLAUSE Y EL «MANDATO INDIVIDUAL»: 2.1. La Commerce Clause en el federalizing process americano; 2.2. El (segundo) nuevo federalismo. Un federalismo potencialmente libertario; 2.3. La Commerce Clause y el concepto de actividad económica: 2.3.1. El fumus boni iure preliminar; 2.3.2. Una decisión libertaria: el Congreso no puede imponer una actividad económica; 2.3.3. Una nueva interpretación de la Necessary and Proper Clause. 3. EL MANDATO INDIVIDUAL Y LA TAXING AND SPENDING CLAUSE: UN PRESIDENTE DEFERENTE HACIA EL PRINCIPIO DEMOCRÁTICO. 4. THE MEDICAID EXPANSION Y LOS LÍMITES DEL FEDERALISMO FISCAL. 5. TRES REFLEXIONES A MODO DE CONCLUSIÓN:

a) La insoportable perseverancia de la objeción contramayoritaria a la justicia constitucional; b) El lenguaje del federalismo y la retórica de los derechos; c) Más retórica federalista: la «soberanía» de los Estados. 


\title{
LA CORTE SUPREMA NORTEAMERICANA Y EL FEDERALISMO DEL BIENESTAR. A PROPÓSITO DEL JUICIO DE CONSTITUCIONALIDAD DE LA REFORMA SANITARIA ${ }^{1}$
}

\author{
VÍCTOR J. VÁZQUEZ ALONSO \\ Profesor de Derecho Constitucional \\ Universidad de Sevilla
}

\section{INTRODUCCIÓN. LA REFORMA SANITARIA: UN HITO LEGISLATIVO ANTE LA CORTE SUPREMA}

En su discurso del Estado de la Unión del año 1944 el presidente Roosevelt daría a conocer uno de los más ambiciosos proyectos de los New Dealers, la conquista de una segunda Bill of Rights en la que se ampliarán las libertades de los ciudadanos norteamericanos, incorporando una serie de derechos de nueva generación que se adecuarían bien al concepto de derechos sociales. Estos derechos conformarían el nuevo horizonte de seguridad y de prosperidad que habían de alcanzar las futuras generaciones de norteamericanos y, entre ellos, se encontraría «el derecho a disfrutar de un adecuado seguro médico y de la oportunidad

${ }^{1}$ La elaboración de este trabajo se ha hecho en el marco del proyecto de «El Nuevo Amparo Constitucional: la Reformulación de los Derechos Constitucionales y su Protección», con referencia DER2010-18141 y financiado por el Ministerio de Ciencia e Investigación. Agradezco igualmente a la Universidad de Fordham la posibilidad que me brindó para poder investigar y discutir sobre este trabajo en el marco de su programa de Visiting Research. 
de disfrutar de una buena salud». Muchos años después, el 10 de Marzo de 2010, el Presidente Obama firmaba The Patient Protection and Affordable Care Act y con ello, una reforma legislativa con la que, por primera vez en su historia, el Congreso de los Estados Unidos daba respuesta a este viejo anhelo de extender la cobertura sanitaria a todos los ciudadanos americanos ${ }^{3}$. Pero lo cierto es que, como veremos en adelante, la reforma sanitaria aprobada por el Congreso no consagra el derecho a la salud, en sentido estricto, sino que lo que en realidad hace es establecer una nueva regulación del mercado de las aseguradoras sanitarias que conduce a que, en la práctica, pueda darse en los Estados Unidos una cobertura sanitaria casi universal. En este sentido, se puede decir que, paradójicamente, la reforma sanitaria, o como la denominaban sus detractores, el Obamacare, consolida lo que le profesor Koppelman ha calificado como una de las «leyendas urbanas» más aceptadas en la cultura política americana, que sería la de que es inviable económicamente en los Estados Unidos un sistema público de salud o, por usar la expresión vernácula, un sistema de single payer 4 .

2 En adelante citaré la ley a través de las siglas ACA, que hacen alusión a la que a la postre ha sido la denominación más utilizada para la reforma: Affordable Care Act.

3 En realidad la cobertura sanitaria universal era una aspiración democrática de la sociedad americana desde hace más de un siglo, cuando el presidente Theodore Roosevelt expresó ante el Congreso su deseo de promover un sistema nacional de salud. Como se ha dicho, esta fue también una de las aspiraciones que formaban parte de la agenda progresista del New Deal, y, posteriormente, fue Truman quien promovió en el Congreso una propuesta para crear un programa nacional de seguro sanitario, si bien la influencia del discurso anti-socialista durante la guerra fría hizo imposible su consagración legislativa, de tal forma que, desde ese momento, Estados Unidos quedó aislado como uno de los pocos países occidentales que no adoptaron un modelo de cobertura pública universal tras la Segunda Guerra Mundial. Esta excepcionalidad fue mitigada con la aprobación durante la presidencia de Lyndon Jonhson de los programas Medicare y Medicaid a través de los cuales se ha financiado con ayuda pública la cobertura sanitaria de ancianos y discapacitados en los Estados Unidos. Ya en la década de los setenta, el senador Eduard Kennedy inició su particular cruzada en el senado para sacar adelante un programa nacional de salud, anunciado por otro lado, tanto por el presidente Nixon como por el presidente Carter. Fue durante la administración Reagan y Bush I, de claro sesgo liberal, cuando la idea de crear un seguro sanitario público perdió definitivamente su vigencia. En este sentido, el intento frustrado de Bill Clinton de extender la cobertura sanitaria a todos los ciudadanos, se basaba ya en la intervención en el mercado privado de aseguradoras, un modelo en el que se inspiró el Congreso de Massachusetts en 2004 para hacer real el acceso al tratamiento médico de los ciudadanos del Estado, que constituye el principal referente de la reforma sanitaria aprobada por el Congreso de la Nación en 2001. Vid. REBECCA E. ZIETLOW, «Democratic Constitutionalism and the Affordable Care Act». 72 Obio State Law Journal, 2001, pp. 1885-1888.

${ }^{4}$ En sentido crítico, es muy interesante el artículo de PABLO DE LORA DELTORO, «La Reforma sanitaria de Obama: entre la pesadilla y el noble sueño», El Cronista del Estado Social y Democrático de Derecho, n. ${ }^{\circ}$ 4, 2010, pp. 42-51. 
A este respecto, a pesar de que la reforma sanitaria no crea un derecho de carácter prestacional a la asistencia sanitaria, lo cierto es que sí facilita, a través de una determinada política pública, que pueda ser una realidad el que la cobertura sanitaria se extienda a una gran mayoría de los ciudadanos. Un logro que no estaba contemplado ni prohibido por la Constitución americana y que, por lo tanto, puede considerarse como un exponente de constitucionalismo democrático americano y del paradigma social que este a veces adquiere en la Historia. En este sentido, la reforma sanitaria no es una ley más, sino que es el resultado legislativo de un esfuerzo democrático específico que se ha enfrentado para su aprobación a todas las adversidades del sistema, lo que permite afirmar que, en cierta medida, con su aprobación se establecía un "precedente» democrático a la hora de interpretar la Constitución por parte de los ciudadanos $^{5}$. Un precedente que, por su carácter inédito y por sus implicaciones políticas y económicas, estaba destinado a entrar en tensión con la propia comprensión que hace la Corte Suprema del papel que ha de desempeñar el Gobierno de la Nación a la hora de garantizar alguno de los pilares básicos del bienestar ${ }^{6}$. Como veremos a partir de ahora, esta tensión habrá de encontrar respuesta jurídica en una decisión de la Corte Suprema que, como si el tiempo no hubiese pasado, va girar en torno a las que pueden considerarse las principales cuestiones constitucionales que, desde el New Deal, han marcado la evolución del federalismo americano en el siglo xx: ¿qué puede considerarse y qué no una actividad económica que afecte al comercio interestatal?, y, ¿cuándo una determinada política fiscal federal dirigida a promover el bienestar de la nación, deja de ser de un incentivo para transformarse en coercitiva para los Estados? Del mismo modo, el juicio de constitucionalidad de la reforma sanitaria, ha situado de nuevo a una institución como la Corte Suprema, dividida internamente y cuya legitimidad es desde la sentencia Bush v. Gore seriamente cuestionada en la opinión pública, ante la difícil tesitura de juzgar lo que puede considerarse un hito legislativo. Todo ello hace de la sentencia National Federation of Independent Business $v$. Sibelius un inmejorable ejemplo de cómo la objeción contramayoritaria a la justicia constitucional puede adquirir también un sentido propio cuando lo que se juzga es la forma en que el legislador ha interpretado las categorías del federalismo.

5 Algo que no era fácil, como bien se explica en la crónica del fracaso de la reforma sanitaria impulsada por la administración Clinton que hacen HAYNES JOHNSON y DAVID S. BRODER, en The System. The American Way of Politics at the Breaking Point, New York, 1996.

${ }^{6}$ Vid. REBECCA E. ZIETLOW, «Democratic constitutionalism and the Affordable Care Act», 72 Obio State Law Journal, pp. 1372-1376. 


\section{LOS FUNDAMENTOS (ECONÓMICOS) DE LA REFORMA}

No cabe duda de que el debate legislativo sobre esta ambiciosa reforma sanitaria fue un debate plagado de argumentos morales y, en concreto, por parte de quienes defendían la necesidad de su aprobación, de argumentos que vinculaban el desarrollo legal de este «derecho a la salud», no sólo a la dignidad de la persona, sino también a la propia plenitud de la ciudadanía, la cual presupondría el acceso universal a unas condiciones mínimas de bienestar ${ }^{7}$. No obstante, si bien es cierto que la reforma sanitaria posee este innegable sustrato moral, también lo es que los instrumentos concretos a través de los cuales esta universalización de la cobertura sanitaria se ha llevado a cabo, se justifican con argumentos marcados por un evidente pragmatismo económico. Resumiendo mucho, el relato de los motivos económicos que ofreció el legislador para aprobar la reforma sería el siguiente ${ }^{8}$.

En los Estados Unidos la inexistencia de un sistema nacional de salud, combinado con el alto coste de los seguros privados y la posibilidad de las compañías de denegar la cobertura o incrementar libremente los costes a las personas que presentasen determinadas condiciones de salud desfavorables, había provocado que casi sesenta millones de ciudadanos vivieran sin seguro médico. Esta bolsa de ciudadanos sin cobertura sanitaria suponía una carga social casi insostenible para el país, como demostraba el dato de que el $62 \%$ de las bancarrotas que se producen en los Estados Unidos tenían precisamente como origen la necesidad de afrontar costes médicos carentes de cobertura sanitaria ${ }^{9}$. Del mismo modo, el propio mercado de los seguros sanitarios había padecido un incremento sustancial de los costes por el hecho de que millones de personas carecían de seguro médico. La razón de ello es que ese gran número de personas que no disfrutan de ningún tipo de cobertura sanitaria en los Estados Unidos va a recibir en muchos casos asistencia de urgencia, ya que la legislación norteamericana exige que se preste ese tipo de asistencia a la personas sin seguro médico ${ }^{10}$. De esta forma, en la mayoría de los casos en los que se prestaba asistencia sanitaria de

7 NEOMI RAO, «American Dignity and Healthcare Reform», 35 Harvard Society for Law E Public Policy, Winter, 2012, pp.171 y ss.

8 Para un análisis detallado de esta reforma desde la perspectiva del federalismo cooperativo, véase, en nuestra doctrina, EVA SÁENZ ROYO, «La reforma sanitaria de Obama en el marco del federalismo», Revista General de Derecho Constitucional, n. ${ }^{\circ} 11,2010$.

${ }^{9}$ Patient Protection and Affordable Care Act, Sec. 18091 A (2) (f).

${ }_{10}$ Esta exigencia fue introducida en 1986 a través del Emergency Medical Treatment and Active Labor y afecta a todos aquellos hospitales que participan en el programa Medicare, lo cual en la práctica supone la gran mayoría de los hospitales del país. 
urgencia a personas sin cobertura médica, no se producía ninguna compensación posterior por la misma, lo cual ocasionaba importantes pérdidas económicas para los hospitales ${ }^{11}$ que estos a su vez repercutían subiendo los precios a las aseguradoras, las cuales, finalmente, lo compensaban incrementando la prima para la adquisición del seguro médico a los ciudadanos americanos.

Pues bien, el sistema que la reforma sanitaria diseña para subvertir esta insostenible situación y, por lo tanto, para universalizar la cobertura médica, descansa sobre dos elementos principales. El primero de ellos es el establecimiento de un mandato individual para que todos los ciudadanos estadounidenses adquieran un mínimo de cobertura sanitaria en el mercado privado de las aseguradoras $^{12}$, de tal forma que aquellos que en el año 2014 no hayan adquirido esta cobertura tendrán que pagar lo que en principio fue entendido como una «sanción», que sería recaudada por el Gobierno Federal a través de los mismos mecanismos que son usados para la recaudación de impuestos ${ }^{13}$. Como correlato lógico a este mandato, la ley prohíbe a las aseguradoras denegar la adquisición del seguro médico o incrementar las primas a aquellas personas que presenten condiciones previas que les hagan más susceptibles de requerir tratamiento médico $^{14}$.

Junto a este mandato individual, la ley va a llevar a cabo una significativa extensión del principal programa federal de ayuda a los estados para la protección del derecho a la salud hasta entonces existente, el conocido Medicaid, promovido en los años sesenta por el presidente Lyndon Jonhson, y que había tenido como beneficiarios a las familias necesitadas, niños, y personas que padeciesen algún tipo de discapacidad. En realidad, excepción hecha de estos supuestos de deficiencias físicas, se puede decir que el Medicaid era un programa concebido para ayudar principalmente a las familias. A este respecto, la gran novedad que introduce el ACA es que se extiende el ámbito de beneficiarios del Medicaid, incluyendo en él a aquellos adultos sin hijos cuyo nivel de renta se encuentre por

11 La Secretaria de Salud y Servicios Humanos había estimado que en 2008 más de 2,1 millones de norteamericanos sin seguro médico alguno había recibido este tratamiento médico de urgencia, que en la gran mayoría de los casos no pudo ser compensado a los hospitales. El coste que total estos tratamientos no retribuidos para los hospitales se había estimado, ese mismo año 2008, en 43 miles de millones de dólares. Vid. Patient Protection and Affordable Care Act, Sec. 18091 A (2) (f).

12 Para cumplir con la exigencia de adquirir este mínimo de cobertura sanitaria, la legislación contempla cuatro vías válidas: a través de aquellos programas financiados con fondos públicos; a través del seguro sanitario que ofrezcan las empresas a sus empleados; mediante pólizas familiares o por medios de la contratación de seguros médicos de exclusiva cobertura individual. Internal Revenue Code, n. ${ }^{\circ} 5000$ A (f)

13 Patient Protection and Affordable Care Act, Sec. 1501.

14 Patient Protection and Affordable Care Act Sec. 2704-2705. 
debajo del $138 \%$ del umbral de la pobreza que haya sido establecido ${ }^{15}$. Dado que con ello el espectro de beneficiarios por el programa se ampliaba considerablemente, la reforma también va a prever un incremento en la financiación federal que recibirán los estados para su implementación. Ahora bien, para asegurarse la cooperación estatal en la implementación del ACA, la ley establece que aquellos estados que decidan no atender a la extensión del ámbito de beneficiarios perderán, no sólo el incremento presupuestario que el Gobierno Federal destine a la atención de estos nuevos colectivos, sino también toda la financiación federal que hasta ese momento percibían a través del Medicaid ${ }^{16}$.

Estos dos elementos —el mandado individual y la extensión del Medicaid - sobre los que, como se acaba de señalar, descansa todo el sistema de cobertura sanitaria universal diseñado por la ACA, han constituido a su vez, desde el inicio de la tramitación parlamentaria de la reforma, el objeto de las principales objeciones tanto desde el punto de vista político, como en lo referido a su adecuación constitucional ${ }^{17}$. Finalmente, la Corte Suprema admitió a revisión una decisión de la Corte de Apelaciones del Circuito número once. Este Tribunal había negado la legitimidad del Congreso bajo la Commerce Clause para imponer el «mandato individual», si bien, había considerado que la extensión del Medicaid un ejercicio válido del poder de gasto del Congreso en base a la Spending Clause. En el juicio sobre la constitucionalidad de la ACA al que se enfrentaba la Corte Suprema, no estaba sólo en juego, como veremos, la viabilidad de este intento de cobertura universal sanitaria, sino también, en buena medida, la propia comprensión del federalismo americano y del papel que puede tener el Gobierno Federal en la implementación de políticas sociales públicas en los estados.

15 Patient Protection and Affordable Care Act, Sec. 2001.

16 Patient Protection and Affordable Care Act, Sec. 2005.

17 Poco después de entrar en vigor la reforma, esta fue objeto del primer desafío judicial a su constitucionalidad en Florida ex rel. Bondi v. U. S. Departament of HealthE Human Services, una demanda en la que se personaron a través del Fiscal General o de sus Gobernadores 26 estados de la Unión. A esta demanda le siguieron otros 27 casos en distintos estados. Seis de ellos terminaron ante las Cortes Federales de Distrito y finalmente tres ante las Cortes Federales de Apelaciones del quinto Circuito (Tomas More Law Center c. Obama) del decimoprimer Circuito (Florida ex rel. Bondi v. U. S. Departament of HealthE Human Services) y del Circuito del Distrito de Columbia (SevenSky v. Holder) El Tribunal del décimo primer Circuito consideró inconstitucional el «individual mandate», si bien entendió que esto no tenía por qué afectar a la vigencia del resto de la reforma introducida por la ACA. La Corte Suprema admitió el certiorary de esta decisión que es el origen de Nacional Federation of Independent Business v. Sibelius. 


\section{LA COMMERCE CLAUSE Y EL «MANDATO INDIVIDUAL»}

\subsection{La Commerce Clause en el federalizing process americano}

Cualquier intento de aproximación al federalismo desde esquemas estrictamente dogmáticos o conceptuales está destinado a la frustración. Y es que, incluso en el contexto de una constitución rígida que determine de una forma nítida la existencia de dos niveles de poder diferenciado, el federalismo siempre va a adquirir una dimensión dinámica, de tal forma que solo si lo entendemos como un proceso ${ }^{18}$ permeable por definición, a las circunstancias históricas y políticas, podremos encontrar un sentido más o menos claro de sus perfiles, los cuales, en cualquier caso, van a tener siempre un importante grado de ductilidad. En este sentido, si bien es cierto que en el corazón del modelo norteamericano de distribución territorial del poder está la idea de que «los poderes del Congreso están definidos y limitados» en la Constitución ${ }^{19}$, también lo es que, ya en la primera mitad del siglo $\mathrm{xx}$, puede decirse que este concepto estricto de los poderes del Gobierno Federal fue superado ${ }^{20}$, abandonándose con ello un concepto dual del federalismo, en beneficio de uno nuevo, acuñado exitosamente por con el adjetivo de cooperativo ${ }^{21}$.

Las razones de este tránsito obviamente no pueden reducirse a una, ni tampoco se puede pasar por alto que la propia comprensión del federalismo ha obedecido a una cierta evolución pendular. En este sentido, no debe obviarse que frente a los representantes Republicanos, la facción Federalista del Primer Congreso ya había defendido una interpretación laxa de las materias sobre las que el Congreso podría legislar bajo la Commerce Clause. Esta fue la posición de Hamilton y también la del propio Juez Marshall como Presidente de la Corte Suprema, quien en 1824 con la sentencia Gibbons v. Ogden sentó las bases para una interpretación plena de los poderes conferidos a la Unión bajo la mencio-

18 Vid. Sobre este concepto, puede verse, en extenso, Carl J. FRIEDRICH, Trends to Federalism in Theory and Practice, New York, 1968. En especial, Capítulo II.

19 Marbury v. Madison, 1 Cranch 137, 176 (1803)

20 Para una crónica de este cambio de paradigma pueden leerse las primeras páginas del clásico de WALTER THOMSON, Federal Centralization. A Study and Criticism of the Expanding Scope of Congressional Legislation, New York, 1923, pp. 3-18.

${ }^{21}$ Véase, por todos, CORWIN, «National-State Cooperation. Its present Possibilities», 46 The Yale Law Journal, 1937, pp. 599 y ss. Como ha señalado Eva Sáenz Royo, en gran medida, la expresión «inter governmental Relations» ha acabado por sustituir al concepto de «federalismo cooperativo» en la literatura norteamericana. Vid. EVA SÁENZ ROYO, «La reforma sanitaria de Obama en el marco del federalismo», op. cit., p. 6, nota 17. 
nada cláusula ${ }^{22}$. En este sentido, la doctrina judicial deferente con los poderes conferidos al Gobierno de la Nación en la Constitución americana que se consolida en la jurisprudencia de la Corte Suprema a partir de la década de los cuarenta del siglo pasado, no fue del todo sobrevenida, sino que su germen teórico se encontraba ya en esta primera jurisprudencia del Tribunal. Sin embargo, fue paradójicamente después de la Guerra Civil y de la aprobación de las Enmiendas de la Reconstrucción —es decir, una vez consolidada la Unión y cuando se empiezan a atisbar las necesidades de coordinación y armonización dentro de una economía cada vez más industrializada - cuando la Corte va ir progresivamente enterrando esta lectura amplia de los poderes conferidos al Congreso bajo la Commerce Clause, para esbozar una teoría estricta del federalismo dual, que limitaba ostensiblemente el poder del Gobierno central en beneficio de los derechos de los estados. Esta lectura restrictiva de los poderes del Congreso coincide con otra estrictamente liberal de las posibilidades de los poderes públicos de intervenir en la regulación de las relaciones económicas que tiene su origen en la conocida sentencia Lochner v. New York, la cual dará nombre, como es sabido, a una larga etapa en la Corte conocida como Lochner's $\mathrm{Era}^{23}$, que estuvo caracterizada por un activismo judicial contrario a la legislación social estatal y federal ${ }^{24}$. Esta interpretación liberal y dualista del federalismo americano marcó la jurisprudencia de la Corte durante más de treinta años, hasta que finalmente la propia Corte Suprema puso fin a una doctrina que padecía una cierta obsolescencia histórica en su comprensión del papel del Estado en la economía y que condujo, no solo a un enfrentamiento directo con el presidente Roosevelt ${ }^{25}$, sino también a la consolidación

${ }^{22}$ Gibbons v. Ogden, 22 U. S. 1 (1824)

${ }^{23}$ Como es sabido, por Lochner Era, se entiende la etapa jurisprudencia que se inicia con la sentencia Lochnerv. New York, 198 U. S.45 (1905), en la cual la Corte Suprema consideró contraria a la Due Process Clause una normativa del Estado de New York que establecía un número máximo de horas semanales de trabajo para los panderos. Deduciendo una comprensión estricta de la libertad contractual, a partir de la Enmienda XIV, la Corte Suprema se convertirá durante tres décadas en el principal escollo de las políticas sociales tanto a nivel estatal como federal, defendiendo un concepto estrictamente liberal del papel que la Constitución reserva a los poderes públicos a la hora de intervenir en la economía. Vid. CASS R. SUNSTEIN, «Lochner's Legacy». 87 Columbia Law Review, pp. 873-919. Para una lectura benévola en clave liberal de esta época del Tribunal puede verse el reciente libro del profesor DAVID E. BERNSTEIR, Rebabilitating Lochner: Defending Individual Rights against Progressive Reform. Chicago: University of Chicago Press, 2011.

24 Vid. por todos, ÉDUARD LAMBERT, Le gouvernement des juges et le lutte contre la legislation social eaux États-Unis, Paris, 2004, en especial, pp. 51-59.

${ }^{25}$ Frente a este activismo judicial contra la legislación social, el Presidente Roosevelt promovió una compleja reforma de la Constitución dirigida a modificar la composición del Tribunal 
en la opinión pública americana de una visión hostil hacia la Corte Suprema hasta entonces inédita ${ }^{26}$.

El nuevo paradigma del federalismo americano se va a construir, en gran medida, sobre una nueva interpretación de la Commerce Clause del artículo uno de la Constitución, que otorga al Congreso de los Estados Unidos el poder «para regular el comercio con las naciones extranjeras, y entre los distintos estados, y con las tribus nativas». La sentencia NLRB v. Jones $\mathcal{E}$ Laughlin Steel, una decisión dictada a propósito de una demanda que cuestionaba la constitucionalidad de Ley Federal de Relaciones Laborales, es, en este sentido, el origen de una verdadera revolución constitucional que modificará radicalmente la comprensión, tanto del papel que los poderes públicos pueden jugar en la vida económica del país, abandonando los presupuestos estrictamente liberales hasta entonces vigentes, como del propio ámbito que Constitución reserva al gobierno central para regular los distintos aspectos de una sociedad industrial moderna a través de políticas nacionales, hasta el punto de que desde 1937, la Corte Suprema nunca ha cuestionado la constitucionalidad de un programa social federal.

Esta nueva doctrina de la Commerce Clause se construye sobre el presupuesto básico de que esta cláusula no solo legitima al Congreso para regular el comercio entre los estados, sino también aquellas actividades económicas cuyo ámbito de desarrollo sea genuinamente intraestatal pero que, a su vez, puedan tener, por su naturaleza, una relación sustancial con el comercio interestatal. En este sentido, la Cláusula de Comercio otorgaría al Gobierno Federal la potestad de regular estas actividades intraestatales que, de no ser reguladas, pueden generan determinadas barreras u obstrucciones en el comercio entre los estados. La sentencia United States $v$. Darby ${ }^{27}$, dictada en 1941 , supuso la consoli-

Supremo y así alterar sus fuerzas. Si bien, tal reforma no fue necesaria puesto que la mayoría del Tribunal cambió de orientación, con el cambio de posición del Juez Roberts quien, en el conocido caso West Coast Hotel c. Parrish 300 U. S. 379 (1937), votó esta vez a favor de la constitucionalidad de la Ley de Salario Mínimo que había aprobado el estado de Washington. Un gesto que a la postre sirvió para frenar la reforma ideada por Roosevelt. Tal y como apuntaron los cronistas políticos de la época «The switch in time that saved nine» (una puntada a tiempo que salvo los nueve) Sobre la intrahistoria de la batalla mantenida por el Presidente Roosevelt con la Corte Suprema y, en general, sobre esta época en la política de los Estados Unidos es excepcional el trabajo, ya clásico de DAVID M. KENNEDY, Entre el miedo y la Libertad. Los EEUU: de la Gran Depresión al fin de la Segunda Guerra Mundial (1929.1945), Barcelona, 2005, pp. 389-419.

26 Vid. BARRY FRIEDMAN, The Will of the People: How Public Opinion Has Influenced the Supreme Court and Shaped the Meaning of the Constitution, New York, 2009, p. 205.

27 Con ello la Corte se aparta de forma explícita de una jurisprudencia que de manera reiterada había afirmado que la Cláusula de Comercio no podía servir de base para la regulación federal 
dación de esta nueva y reduccionista compresión constitucional de lo local en el ámbito económico que enfatiza la idea de que en un mercado nacional los estados no son capaces por sí solos de ofrecer una respuesta satisfactoria a los problemas de carácter macroeconómico ni a los riesgos que afectan al país y a sus ciudadanos ${ }^{28}$. Cuándo existen estas disfunciones o riesgos a nivel federal y cuál es la respuesta legislativa que ha de darse son cuestiones que no han de decidir los jueces sino que preferentemente lo harán conjuntamente todos los estados representados en el Senado y a través del procedimiento legislativo. Una doctrina que es llevada un poco más allá por la Corte en Wickard v. Filburn, una decisión que estableció el precedente de que cuando la suma agregada de ciertas actividades económicas individuales pueda tener efectos sustanciales sobre el comercio nacional, el Congreso está legitimado para establecer una regulación que afecte singularmente a cada una de estas actividades económicas, incluso cuando las mismas no estén destinadas al intercambio comercial ni tengan, aisladamente consideradas, efecto alguno sobre el mercado interestatal ${ }^{29}$.

A principios de la década de los cuarenta, por lo tanto, a través de una nueva interpretación de la Commerce Clause, y sin necesidad de modificar el reparto de competencias establecido en la Constitución, se había producido un cambio radical en la comprensión del federalismo americano ${ }^{30}$. Ahora bien, reducir las implicaciones de este cambio únicamente a su dimensión económica o estructural, nos estaría dando una versión más que parcial de las consecuencias que esta nueva comprensión de los poderes del Congreso en la Constitución trajo consigo en el ordenamiento jurídico norteamericano. Y es que la Cláusula de Comercio no solo ha servido para que el Congreso de los Estados Unidos haya homogeneizado las condiciones de producción en el mercado nacional, sino

de actividades no propiamente de intercambio comercial ni tampoco de aquellas cuyos efectos en el comercio interestatal fueran solo de carácter indirecto, lo cual excluía que el Gobierno central pudiera intervenir legislativamente en las condiciones de trabajo de los productos manufacturados. Para un resumen de esta doctrina puede verse Schechter Poultry Corporation v. United States 295 U. S. 495 (1935)

${ }^{28}$ Una decisión en la que la Corte Suprema considera que se encuentra dentro de los poderes que la Constitución otorga al Congreso bajo la Cláusula de Comercio, no sólo el prohibir el transporte de productos que han sido producidos dentro de los Estados bajo ciertas condiciones laborales que no alcancen unos ciertos estándares de seguridad, salubridad y protección, sino también la propia prohibición de estas condiciones de trabajo dentro de los estados, independientemente de que los bienes producidos bajo las mismas estén destinados al comercio interestatal United States v. Darby, 312 U. S. 100, 121 (1941)

29 Wickard v. Filburn, 317 U. S. 111 (1942)

30 Vid. BRUCE ACKERMAN, We the People. Foundations, 1991, pp. 34-57. 
también para que se introdujese legislativamente una verdadera revolución moral en el ordenamiento que alcanzó al propio estatuto de derechos de los ciudadanos. Hay que tener presente, en este sentido, que el grueso de la legislación antidiscriminatoria —incluida la propia Civil Rights Act de 1964-con la que, en los años sesenta, se dada una respuesta federal a las conocidas Jim Crow Policies de algunos estados del sur de la Unión, encontró su fundamento constitucional no como desarrollo legislativo de las enmiendas de la Reconstrucción ${ }^{31}$, sino en el poder conferido al Congreso por la Commerce Clause. El tránsito del federalismo dual al federalismo cooperativo adquiría, en este sentido, un innegable y sobrevenido estatus moral que cuestionaba en gran medida el presupuesto madisoniano de que sería a partir de los Estados como se garantizaría la libertad y bienestar de los ciudadanos ${ }^{32}$. Esto, de alguna forma, también explica por qué durante años existió una cierta condescendencia crítica con la interpretación expansiva de la Cláusula de Comercio que desarrolló la Corte Suprema. Y es que, en definitiva, bajo la jurisprudencia Darby-Wickard cualquier problema local que pudiese ser considerado por los representantes en el Congreso como un problema que afectara sustancialmente al mercado nacional, podía ser objeto de regulación federal, de tal forma que, tal y como concluyera Tribe en la edición de 1978 de su manual de Derecho Constitucional, «la conciencia común era que, desde 1937, no existía la posibilidad judicial de controlar la acción del Congreso a través de los límites del federalismo. La única protección de los Estados era política» ${ }^{33}$.

\subsection{El (segundo) nuevo federalismo. Un federalismo potencialmente libertario}

La deferencia sistemática hacia los poderes del Congreso que caracterizó la jurisprudencia de la Commerce Clause desde la década de los cuarenta, va a ser matizada por la Corte Suprema a partir de la muy conocida United States $v$. $L_{o p e z}{ }^{34}$, una sentencia sin duda clave a la hora de delinear los perfiles del nuevo «nuevo federalismo» con el que durante los años de la Corte Renhquist se quiso recuperar para los estados un ámbito originario de autonomía frente al Gobierno Federal $^{35}$. La normativa federal cuestionada en este caso, era la Gun

31 Vid. Heart of Atlanta Motel v. U. S., 379 US, 241; (1964) Katzenbach v. McClung, 379 U. S. 294 (1964)

32 El Federalista XLV.

33 LAURENCE H. TRIBE, American Constitutional Law, New York, 1978, p. 300.

34 United States v. Alfonso Lopez, Jr., 514 U. S.549 (1995).

35 Vid. SUE DAVIS, Justice Rehnquist and the Constitution, Princeton, New Jersey, 1989, pp. $135-188$. 
Free School Zones Act, a través de la cual, el Congreso de los Estados Unidos había tipificado penalmente la posesión de armas en las zonas escolares o próximas, basándose en el argumento de que este tipo de actividades tenían efectos en el comercio interestatal $^{36}$. La opinión de la Corte en la sentencia López, que redacta el propio Renhquist, resume muy bien el cuadro analítico que había sido establecido en los precedentes que conformaban la jurisprudencia de la Commerce Clause después de la era Lochner, y que concreta el poder del Congreso lo siguiente:

Primero: El congreso puede regular los canales del comercio interestatal.

Segundo: El congreso está legitimado para regular y proteger los instrumentos del comercio interestatal, o las personas o cosas en el comercio interestatal, también cuando la amenaza pueda proceder solo de actividades intraestales.

Tercero: la autoridad del Congreso bajo la Commerce Clause también incluiría el poder para regular aquellas actividades que afecten sustancialmente al comercio interestatal. Para lo cual, habría que tener presente que según lo establecido por la Corte en Wickard el efecto acumulativo que una actividad económica individual, incluso de carácter intraestatal pudiese tener en el comercio entre los estados.

Como ha sido señalado por algún autor, la sentencia López no altera en realidad el marco conceptual a la hora de analizar si el Congreso se ha excedido o no de los poderes conferidos por la Constitución ${ }^{37}$, sino que lo que hace es, en cierta medida, reactivar el último de los elementos del test, posibilitando un juicio real sobre si la actividad regulada, puede o no considerarse una actividad económica con efecto sustancial sobre el comercio interestatal, de tal forma que no sea solo el Congreso quien determine esto a través del proceso político. Lo amparado y lo no amparado por la Cláusula de Comercio volvió así a situarse desde López en la esfera de indeterminación propia de las categorías competenciales del federalismo, lo que significaba, al mismo tiempo, que los jueces recuperaban un papel central a la hora de salvaguardar aquel ámbito de poder reservado a los Estados $^{38}$. La indiscutible inseguridad que produce someter el

36 En concreto, el Congreso había argumentado que los costes relacionados con la violencia que podía derivarse de la posesión de armas en estas zonas, constituían acumulativamente un problema para la economía nacional que legitimaba una solución federal; y, en segundo lugar, que la violencia en las escuelas afectaba al proceso educativo, lo cual constituía un problema nacional de innegable dimensión económica.

37 Vid. FERNANDO REY, United States v. López y el «Nuevo federalismo norteamericano», Revista Española de Derecho Constitucional, n. ${ }^{\circ}$ 51, Septiembre-Diciembre, 1997, p. 297.

38 Véase, entre otros, DONALD H. REGAN, «How to Think about the Federal Commerce Power and Incidentally Rewrite United States v. Lopez», 94 Michigan Law Review554, 1995, 
resultado del proceso político al control judicial, bajo las normas de distribución del poder establecidas por la Constitución, se justifica sobre la idea de que erradicar esta falta de certeza sobre lo que la Constitución dice, significaría también acabar con el modelo de poderes acotados y enumerados establecidos por la Constitución de los Estados Unidos ${ }^{39}$. La tipificación de la posesión de armas en tanto es una medida de política criminal, se encontraría dentro de un ámbito que tradicionalmente se ha reservado a los Estados, y que se ha de oponer, en supuestos como estos, a los intentos del Congreso de justificar una especie de poder general sobre cualquier materia.

Esta línea jurisprudencial abierta en Lopez tuvo una importante secuela en United States v. Morrison ${ }^{40}$, donde la Corte Suprema hubo de decidir si una normativa federal sobre violencia de género - Violence Against Women Act- puede ampararse o no en el poder que la Commerce Clause otorga al Congreso. Para el Congreso existía una «relación sustancial» entre la actividad regulada y el comercio interestatal, máxime si se tomaba en consideración el efecto agregado de este tipo de conductas. Pues bien, la Corte Suprema no sólo va a negar la existencia de esta relación sustancial, sino que además va a insistir en un argumento que será determinante en la interpretación futura de la Cláusula de Comercio y, en concreto, en el juicio de constitucionalidad de la reforma sanitaria, y este es el de que la violencia de género no puede considerarse una actividad económica, con lo cual, no es ni siquiera necesario contemplar el efecto agregado que pueda tener en el comercio interestatal ${ }^{41}$. Por lo tanto, desde Morrison, el poder del Congreso bajo la Commerce Clause para regular una actividad, parece presuponer, en primer lugar, que exista una verdadera actividad y, en segundo lugar, que la actividad posea un carácter económico. Con las matizaciones introducidas por la Corte en Morrison es evidente que el principio de que la «Constitución requiere una distinción entre qué es realmente nacional y que es verdaderamente local», se había visto reforzado y con ello, el papel del juez a la hora de definir la distribución territorial del poder entre el Gobierno Federal y los Estado en esas denominadas zonas de penumbra.

Pero, más allá de supuestos como López o Morrison, donde la naturaleza de la ley impugnada favorecía su consideración como materia propia de los estados, esta doctrina más restrictiva de los poderes conferidos al Congreso bajo la Commerce Clause, se prestaba a una interpretación individualista y defensiva frente a

p. 555; ANN ALTOHUSE, «Enforcing Federalism After United States v. Lopez», 38 Arizona Law Review 793, 1996, p. 817.

39 United States v. Alfonso Lopez, Jr., 514 U. S. 549, 566 (1995).

40 United States v. Morrison, 529 U. S. 598 (2000).

41 United States v. Morrison, 529 U. S. 598, 610 (2000). 
determinadas obligaciones impuestas desde el Gobierno Federal que pudiesen afectar a ciertos ámbitos de libertad, que desde el fin de la era Lochner, no habían sido objeto de amparo a través de la Substantive Due Process of Law Clause ${ }^{42}$. Así, al prestigio moral que desde la década de los sesenta poseía el federalismo PostNew Deal, empezaba a oponérsele un discurso crítico que se sustenta precisamente en la idea de que el mismo, rompiendo el equilibrio de poder entre la federación y los estados, había puesto en riesgo algo que forma también parte del sustrato moral básico de la cultura política americana desde sus orígenes, como es el escrupuloso respecto de la autonomía personal. La retórica del libertarismo redescubría de este modo la Commerce Clause como una herramienta argumentativa que, a través de la idea de que los poderes de la Unión son reducidos, podía, en ciertos casos, instrumentalizar la defensa de la soberanía de los Estados al servicio de una determinada concepción de la relación entre el individuo y los poderes públicos.

\subsection{La Commerce Clause y el concepto de «actividad económica»}

Que millones de ciudadanos norteamericanos no tuvieran seguro médico constituía para el Congreso de los Estados Unidos uno de los principales problemas económicos del país a nivel federal. Esto, traducido al lenguaje propio de la Commerce Clause, significaría que la suma agregada de los problemas económicos planteados por la circunstancia de que determinadas personas carezcan de seguro tiene un efecto sustancial en el comercio interestatal, lo cual, en principio, legitimaba al Congreso bajo la Commerce Clause para regular este comportamiento económico. Ahora bien, la pregunta es si, realmente, puede afirmarse que una conducta que se define en negativo — no tener seguro médico-, constituye una actividad económica que pueda ser regulada por el Estado, de tal forma que se exija a quienes voluntariamente habían decido no adquirir un seguro médico, participar en el mercado de los seguros adquiriendo uno. Pues bien, esta pequeña disquisición acerca de si el no tener seguro médico es o no subsumible dentro del concepto de actividad económica, es la que, en principio, estaba destinada a determinar la respuesta a la pregunta de si el Congreso estaba amparado por la Constitución para imponer a los ciudadanos el mandato individual de participar en el mercado de los seguros sanitarios.

42 Puede verse, a este respecto, DAVID E. BERNSTEIN, «Lochner Era Revisionism, Revised: Lochner and the Origins of Fundamental Rights Constitutionalism» 82 Georgetown Law Journal, n. ${ }^{\circ}$ 1, 2003; JACK BALKIN, «Lochner and Constitutional Historicism», 95 Boston University Law Review 85, 2005, en especial, pp. 687-696. 


\subsubsection{El fumus boni iure preliminar}

Creo que puede decirse que en la academia y en la propia opinión pública americana existía, tras la aprobación del ACA, una suerte de optimismo acerca de las posibilidades de que la Corte avalara la constitucionalidad del individual mandate como una expresión legítima del poder conferido al Congreso a través de la Cláusula de Comercio. Es más que probable que detrás de este optimismo preliminar se escondiesen razones meramente pragmáticas, relacionadas con las previsibles cautelas que la Corte debía de mantener frente a una ley políticamente tan significativa. No obstante, para muchos autores la reforma tenía también, desde el punto de vista jurídico, una clara apariencia de buen derecho bajo la Commerce Clause $^{43}$. La defensa de su constitucionalidad partía, por lo general, de un argumento común que era el de que en una economía integrada como la estadounidense, un problema económico federal necesitaba también de una solución federal. Tal y como la propia Corte Suprema había afirmado en 1944, por su dimensión y características, no puede encontrarse en los Estados Unidos «un sector económico que afecte a los mercados nacional y federal de forma tan variada y tan obvia ${ }^{44}$ » como el sector de los seguros médicos. Por lo tanto, el que millones de ciudadanos carecieran de seguro médico constituía un problema económico genuinamente nacional, y el hecho mismo de que solo Massachusetts hubiera podido sacar adelante un programa que paliase esta situación, garantizando la cobertura sanitaria de sus ciudadanos ${ }^{45}$, podía ser considerado en sí mismo un buen indicio de que no había una posibilidad de ofrecer una solución

43 Así lo defendieron, entre otros, LAURENCE H. TRIBE, «The Constitutionality of the Patient Protection and the Affordable Care Act: Swimming in the Stream of Commerce», 35 Harvard Journal of Law and Public Policy, summer 2012; ANDREW KOPPELMAN, «Bad News for Mail Roberts: The Obvious Constitutionality of Health Care Reform», 121 Yale Law Journal Online, April 26, 2011; ER WIN CHEMERINSKY, «A defence of the Individual Mandate», 62 Mercer Law Review 605, Winter, 2011; RONALD DWORKIN, «Why Health Care Challenge is Wrong», The New York Review of Books, 2 April, 2012; MARK A. HALL, "Commerce Clause Challenges to Health Care Reform», 159 University of Pennsylvania Law Review, June, 2011; DAVID ORENTLICHER, «Constitutional Challenges to the Health Care Mandate: Based in Politics, not Law», 160 University of Pennsylvania Law Review 19, 2011; GUILLIAM METZGER, «Defence of the Constitutionality of Health Care Reform», 62 Mercer Law Review 605, Winter, 2011.

44 Vid. United States v. Se. Underwriters, 322 U. S. 533, 540 (1944) La propia ley cita este precedente como fundamento de la competencia del Congreso. Vid. Patient Protection and Affordable Care Act, Sec. 18091 A (3).

45 Una breve pero precisa descripción de los logros alcanzados por la reforma sanitaria de Massachusets la podemos encontrar en el editoria del New York Times: «Health Reform in Massachusetts», May 20, 2011, http://www.nytimes.com/2011/05/21/opinion/21sat1.html 
eficaz a este problema sino a nivel federal ${ }^{46}$. Por otro lado, a diferencia de lo que, como hemos visto, ocurría en Lopez y Morrison, en este caso no era necesario llevar a cabo elucubraciones casuísticas para relacionar el efecto económico pernicioso que tenía sobre la economía nacional, el hecho de que millones de americanos carecieran de seguro sanitario ${ }^{47}$. Se trataba de un problema de innegable dimensión económica y solucionar este tipo de problemas a través de una respuesta única y eficaz sería, precisamente, el sentido primario que adquieren los poderes que The Framers quisieron ofrecer al Congreso con la consagración constitucional de la Commerce Clause.

La especificidad del mercado sanitario fue también usada para relativizar en el caso concreto, la diferencia entre quién es económicamente activo y quién no dentro de este sector de la economía. Para diversos autores, lo importante realmente sería que, a diferencia de lo que ocurre en cualquier otro sector, en el ámbito de la salud, ningún ciudadano puede realmente permanecer al margen de este mercado. Y es que, utilizando una expresión de Tribe, todos los ciudadanos de los Estados Unidos «nadarían en el río del mercado sanitario», en tanto que tarde o temprano, no hay persona que no vaya a necesitar de atención médica a la largo de su vida ${ }^{48}$. Por lo tanto, si todos están dentro de este mercado se quiera o no, la única diferencia radicaría en que unos ciudadanos lo hacen bajo la cobertura de un seguro sanitario y otros no ${ }^{49}$, y desde el punto de vista jurídico, lo realmente trascendente sería que quien no tiene un seguro ha tomado una decisión acerca de cuándo y cómo accede al mercado sanitario $^{50}$ y que esta decisión, considerada de forma agregada, tiene el efecto de provocar un desajuste sustancial en la economía nacional ${ }^{51}$, ya que en la mayoría de los casos, estas personas no podrán costear los gastos originados por sus tratamientos.

Finalmente, incluso aceptando que la Commerce Clause no ofrecía al Congreso el poder para imponer el mandato individual de adquirir un seguro médico, gran parte de la doctrina americana encontraba el fundamento jurídico a este

46 Vid. ANDREW KOPPELMAN, «Bad News for Mail Roberts...» op. cit., pp. 14-15.

47 Vid. ERWIN CHEMERINSKY, «A defense of the Individual...» op. cit., p. 619.

48 Vid. LAURENCE H. TRIBE, «The Constitutionality of the Patient...» op. cit., p. 880.

49 Vid. JACK M. BALKIN, «Commerce», 109 Michigan Law Review 1, 2010, p. 47.

${ }^{50}$ En este sentido, véase, MARK A. HALL, «Commerce Clause Challenges...» op. cit., p. 1934.

51 Tribe rechaza también cualquier significado jurídico de la diferenciación entre «prohibir» $\mathrm{u}$ «obligar» en el ámbito de la Commerce Clause, acudiendo al precedente establecido por el Juez Marschall en Gibbons v. Ogden 22 U. S 1, (1824). En opinión del autor, el Gobierno tiene el poder de dictar leyes que regulen el comercio interestatal, y no existe otra limitación que las que se deriven de la propia protección de otros bienes constitucionales. 
mandato en otro título competencial de la Constitución, la Neccesary and Proper Clause, en virtud del cual, el Congreso puede aprobar aquella legislación que sea necesaria y adecuada para ejecutar políticas que se encuentren en el ámbito material de alguno de los poderes que la Constitución de los Estados Unidos otorga al Gobierno Federal ${ }^{52}$. Como es conocido, la primera interpretación que hace la Corte Suprema de esta Cláusula se remonta a la emblemática sentencia del Juez Marshall en McCulloch v. Maryland, en la cual, el Tribunal abraza en gran medida las tesis de Hamilton, favorables a interpretar de forma extensiva los poderes que la Constitución de los Estados Unidos confiere al Gobierno Federal, de cara a poder garantizar la unidad económica de la nación, a través, en este caso, de la creación de un segundo Banco Nacional ${ }^{53}$. A diferencia de los Artículos de la Confederación, en los que se rechazaba que el Gobierno de la Nación dispusiera de algún poder no explícitamente otorgado, la Corte Suprema interpretó que, en el nuevo marco constitucional, el Congreso sí disponía de poderes implícitos, es decir, sobre materias no enumeradas en la Constitución, siempre y cuando el ejercicio de estos estuviese vinculado a otros poderes que la Constitución reserva al Gobierno Federal. Conferir estos poderes implícitos al Congreso habría sido, por lo tanto, la razón de ser de la aprobación de la Necessary and Proper Clause. Con base en esta idea, desde McCulloch v. Maryland se había venido avalando la constitucionalidad de aquellas normativas aprobadas por el Congreso de la Nación sobre ámbitos materiales en los cuales este carecía de una competencia expresa. Todo ello siempre y cuando la normativa estuviera dirigida a implementar una política circunscrita a alguno de los poderes reservados por la Constitución al Gobierno Central ${ }^{54}$. En la práctica, la aplicación judicial de la Necessary and Proper Clause se ha llevado a cabo a través de un rational basis test, de tal forma que, para valorar si hay o no tal necesidad, se examina si existe un vínculo racional de adecuación entre la medida concreta que se adopta a través de la ley y la realización de una determinada política que se encuentra amparada por alguno de los poderes que la Constitución otorga

52 U. S Constitution Art.1 Sec. 8. C. 18 ...To make all Laws which shall be necessary and proper for carrying into Execution the foregoing Powers, and all other Powers vested by this Constitution in the Government of the United States, or in any Department or Officer thereof.

53 Vid. RANDY E. BARNNETT, «The Original Meaning of the Necessary and Proper Clause», 6 University of Pennsylvania of Constitutional Law 183, November, 2003, pp. 188-196.

54 «Let the end be legitimate, let it be within the scope of the Constitution, and all means which are appropriate, which are plainly adapted to that end, which are not prohibited, but consistent with the letter and spirit of the Constitution, are constitutional.»McCulloch v. Maryland, 17 U. S.316 (1819) 
al Gobierno Federal ${ }^{55}$. En cualquier caso, lo cierto es que la Corte Suprema nunca había interpretado de una forma excesivamente intensa el concepto de necesidad sino más bien al contrario. Lejos de exigir que la normativa en cuestión fuera absolutamente esencial para la ejecución de alguno de los poderes que la Constitución confiere al Congreso, se había limitado a comprobar, simplemente, si existía en la práctica una «razonable» relación de adecuación o utilidad entre la medida aprobada y el fin constitucionalmente legítimo que se quería conseguir ${ }^{56}$. En este caso, dado el carácter indispensable del mandato individual para la puesta en marcha del conjunto de la reforma, esa relación «razonable» de adecuación al fin era, para muchos autores, indiscutible en este caso.

\subsubsection{Una decisión libertaria: el Congreso no puede imponer una actividad económica}

Frente a los argumentos que acabamos de señalar, la sentencia va a rechazar que la Commerce Clause legitime al Congreso para obligar a los ciudadanos americanos a contratar un seguro médico. Para ello la mayoría del Tribunal parte de un presupuesto expreso y este es que «el poder para regular el comercio presupone la existencia de una actividad para ser regulada». Afirmado esto, la pregunta sería la siguiente: ¿puede considerarse el comportamiento de quien no contrata un seguro médico una actividad? Para la mayoría de los jueces de la Corte, no. La sentencia parte de un presupuesto claro que es el de que entre hacer algo y no hacer algo hay una diferencia radical, independientemente de que en un contexto determinado, como es el que nos ocupa, la inactividad pueda tener desde el punto de vista económico, unas consecuencias tan importantes como la actividad. Del mismo modo, el Tribunal también va a rechazar uno de los principales argumentos esgrimidos a favor de la competencia del Congreso que era, como hemos visto, el de que el mercado sanitario constituye un mercado específico, en tanto todos los ciudadanos tarde o temprano van a participar en él. Para la Corte, la Commerce Clause no permite esa compresión temporal en base a la cual el

55 Sabri v. United States, 541 U. S. 600

56 A este razonable vínculo entre la actividad regulada y el comercio interestatal había a aludido el Juez Scalia en su opinión concurrente Morrison, si bien, al contrario de aquella ocasión, en este caso no entendió que la normativa podía ampararse en la Necessary and Proper Clause: «Congress may regulate even non economic local activity if that regulation is a necessary part of a more general regulation of interstate commerce. The relevant question is simply whether the means chosen are reasonably adapted to the attainment of a legitimate end under the commerce power» Gonzales v. Raich 545 U. S. 1, 37 (2005) 
Congreso estaría legitimado para proyectar su poder sobre las actividades económicas presumibles en el futuro. Además, en su opinión, esta compresión podría ser extrapolada a muchos otros ámbitos, dado que todos somos potenciales compradores de gran cantidad productos a lo largo de nuestras vidas, lo cual podría conducir a situaciones no sólo absurdas sino constitucionalmente intolerables. Por lo tanto, para el Tribunal, la Cláusula de Comercio otorga al Congreso un poder para regular actividades económicas ciertas y actuales ${ }^{57}$ que además tengan efectos sustantivos en el comercio interestatal, pero en ningún caso aquellas futuribles por muy previsibles que estas puedan ser. La Corte insiste, en este sentido, en que nunca había cruzado en su deferencia hacia el gobierno central $^{58}$, la línea que distingue la regulación de determinadas actividades de la imposición de las mismas ${ }^{59}$. Para la mayoría de los jueces, de superarse esa línea, se estaría otorgando al Congreso un poder inédito y potencialmente inabarcable para poder regular en el futuro lo que las personas han de hacer ${ }^{60}$. Admitir que el Congreso, por mucha base racional que tenga, pueda obligar a los ciudadanos a adquirir algo porque es bueno para ellos ${ }^{61}$ o para la economía del país ${ }^{62}$, impli-

57 Para el Tribunal los padres de la Constitución, «no eran filósofos metafísicos» sino «pragmáticos hombres de estado», que tenían muy clara la diferencia que existe entre hacer algo y no hacerlo, y por eso no quisieron otorgar al Congreso el poder para obligar a los ciudadanos a participar en el comercio. Vid. National Federation of Independent Business v. Sibelius, 567 U. S. _, 21 (2012)

58 En este sentido, puede decirse que tal y como había sugerido el juez Kennedy, el hecho de que hasta entonces el Congreso no había explorado la posibilidad de exigir una conducta económica cuando cierta inactividad afectase de manera ostensible al comercio interestatal, sirvió en cierta medida para invertir la presunción de constitucionalidad de la ley en el juicio de la Corte Suprema »Transcript of Oral Argument at 11-12, Dep't of Health \& Human Servs. v. Florida, 132 S. Ct. 2566 (2012) (No. 11-398) http://www.supremecourt.gov/oral_arguments/argument_ transcripts/11-398-Tuesday.pdf.

59 La Corte, subrayando el carácter inédito del litigio constitucional, elude replantearse y en su caso derogar el precedente establecido en Darby y Wickard, tal y como había sugerido algún autor. Vid. RICHARD A. EPSTEIN, «Obama Care vs. The Commerce Clause» en Defining Ideas, Hoover Institution Journal, Stanford University, disponible en http://www.hoover.org/publications/ defining-ideas/article/100456.

60 Vid. PAUL CLEMENT, «The Patient Protection and Affordable Care Act and Breadth and Depth of Federal Power», 35 Harvard Journal of Law E Public Policy 887, Summer, 2012.

${ }^{61}$ Vid. National Federation of Independent Business v. Sibelius, 567 U. S. _, 23 (2012).

${ }^{62}$ El Tribunal no duda en usar uno de los argumentos que más juego habían dado en el debate previo a la sentencia, el denominado The Broccoli Argument. La exitosa tesis del broccoli había sido formulada por el Juez del Distrito de Florida Roger Vinson y resume en lo siguiente. Es evidente que las personas que llevan unos hábitos dietéticos saludables, tienen muchas menos posibilidades de padecer ciertas enfermedades que otras. Por ello, igualmente, puede decirse que el gasto sanitario que estas personas van a causar es con toda probabilidad menor que el de 
caría, en definitiva, transformar radicalmente el lugar del individuo en la Constitución, o, utilizando las palabras de uno de los autores más críticos con la reforma sanitaria, sentar las bases para convertir a los ciudadanos en súbditos, algo que en ningún caso podría admitir el máximo órgano judicial de la Nación ${ }^{63}$.

\subsubsection{Una nueva interpretación de la Necessary and Proper Clause}

En último término, la mayoría de los jueces del Tribunal también rechazan que el «mandato individual» encuentre fundamento en los poderes que se derivan de la Necessary and Proper Clause. Como ya se ha señalado, bajo esta Cláusula el Congreso dispondría de aquellos poderes que pueden servir de forma incidental para alcanzar las finalidades propias a las que responden los poderes enumerados que la Constitución otorga al Gobierno federal. No se trata, por lo tanto, de poderes que tengan una legitimidad explícita y sustantiva desde la Constitución, sino que están vinculados a la consecución de otros poderes constitucionales. En principio, es el Congreso de los Estados Unidos quien ha de determinar qué medidas son necesarias para la puesta en práctica de las políticas para las que constitucionalmente está legitimado. Y lo cierto es que a la luz de los adjetivos con los cuales la Corte suprema ha cifrado el grado de necesidad: convenient, useful, conducive... puede comprobarse que siempre ha existido una particular deferencia hacia el principio democrático por parte de los jueces. Sin embargo, en este caso, la Corte introduce una visión bastante más estricta del ámbito permitido por la Constitución para que el Congreso actúe sobre materias vinculadas incidentalmente a sus poderes. Para ello, parte del presupuesto de

las segundas. Es más, si todas las personas llevaran hábitos alimenticios saludables, el gasto sanitario sería mucho menor, ya que las compañías no tendrían que prever grandes costes por asegurado, lo cual liberaría a los ciudadanos americanos de gran parte de la pesada carga económica que supone un seguro, abaratando en su conjunto el mercado interestatal de los seguros médicos. En este sentido, para la Corte, si aceptamos que se puede exigir a los ciudadanos que adquieran un producto concreto como es el seguro sanitario, con el argumento de que esto mejorará razonablemente el mercado interestatal de seguros, habría que aceptar, por esa misma razón, que el Congreso pueda obligar a los ciudadanos a adquirir y consumir alimentos saludables como el Brócoli, o, de la misma forma, y teniendo en cuenta las necesidades de la industria nacional de automóvil, a comprar coches de la General Motors. Vid., State of Florida by and through Attorney General Pam Bondi v. United States Department of Health and Human Services, 780 F. Supp. 2d 1256.

${ }_{63}$ Vid. National Federation of Independent Business v. Sibelius, 567 U. S._, 23, 24 (2012) Vid. RANDY E. BARNETT, «Turning Citizens into Subjects: Why the Health Insurance Mandate is Unconstitutional», 62 Mercer Law Review 605, Winter, 2011, pp. 608-609. 
que no cabe ninguna interpretación de la Necessary and Proper Clause que legitime lo que no serían sino simples actos de usurpación de los poderes de los Estados. Es decir, que no sólo es necesario juzgar si el ámbito sobre el que el Congreso reclama su competencia puede vincularse al ejercicio de alguno de los poderes sustantivos que le confiere la Constitución, sino que además, y antes que nada, hay que juzgar si ese ámbito forma parte de los atributos de la soberanía de los estados, con lo cual dejaría de poder considerarse un poder inciden$\mathrm{tal}^{64}$, para ser considerado un «poder independiente y sustantivo» que solo de haberse enumerado en la Constitución a favor del Congreso podría haber sido ejercido.

Esta interpretación que hace la Corte de la Necessary and Proper Clause no puede pasar inadvertida. Hasta ahora se había interpretado que cuando de forma razonable se pudiera justificar la necesidad de una determinada medida legislativa (exigir el seguro) para llevar a cabo un fin amparado por los poderes que la Constitución otorga al Gobierno Federal (regular el mercado de los servicios sanitarios), la constitucionalidad de la normativa debía de ser amparada. Sin embargo, en esta ocasión, la Corte distingue entre el significado jurídico de Necessary y de Proper, para afirmar que si bien la medida puede ser considerada «necesaria», en ningún caso es «adecuada», y ello porque pisa un terreno que no guarda ninguna relación con los poderes otorgados al Congreso por la Constitución y, en concreto, por la Commerce Clause ${ }^{65}$; introduciéndose en ámbitos que constituyen «esenciales atributos de la soberanía de los estados» ${ }^{66}$. Este cambio de doctrina tiene un importante relevancia práctica y es que, hasta ahora, la

${ }^{64}$ Vid. GARY LAWSON, DAVID B. KOPEL, «Bad News for Professor Koppelman: The Incidental Unconstitutionality of The Individual Mandate», 121 Yale Law Journal Online 267, en especial, pp. 281-283 y 287 y ss.

65 Exactamente, la Corte considera que el «mandato individual» no es Proper porque «undermines the structure of government established by the Constitution». National Federation of Independent Business v. Sibelius, 567 U. S.33 (2012).

${ }^{66} \mathrm{La}$ Corte cita como precedentes las sentencias Printz v. United States, 521 U. S. 898 (1997) y New York v. United States 505 U. S. 144 (1992). En ambas sentencias la Corte descartó que la legislación federal pudiera ampararse en la Necessary and Proper Clause, por vulnerar la soberanía de los estados. El juez Ginsburg fue muy crítico en su voto particular con esta jurisprudencia traída a colación por la mayoría del Tribunal. En ambos casos se trataba de leyes federales que obligaban a los funcionarios de los estados a asumir determinadas obligaciones. Por ello, en su opinión, no podía hacerse ninguna analogía con la normativa que imponía el «individual mandate», el cual no iba dirigido a las instituciones estatales ni a sus funcionarios, sino a los ciudadanos. Por otro lado, para Ginsburg, la Corte había obviado que este mandato individual estaba estrechamente vinculado a una política nacional proyectada sobre un sector en el que los estados se habían mostrado incompetentes para regularlo satisfactoriamente por separado. Una circunstancia que necesariamente tenía que incidir en el juicio de acerca de la 
finalidad constitucional de la Necessary and Proper Clause era precisamente conferir al Congreso poderes implícitos, es decir, competencias que la Constitución no le otorgaba expresamente pero que sí resultaban incidentales al ejercicio de otros poderes expresamente otorgados. Tras esta sentencia, parece deducirse que la Necessary and Proper Clause alude a facetas del poder ya latentes en la lista de poderes enumerados a favor del gobierno federal, con lo cual, la Cláusula adquiere un cierto carácter redundante, en tanto, simplemente serviría para reafirmar poderes que la Constitución ya otorga expresamente al Congreso, tal y como había sostenido Madison a propósito del debate sobre la creación de un Banco Nacional durante el Primer Congreso ${ }^{67}$.

\section{EL MANDO INDIVIDUAL Y LA TAXING AND SPENDING CLAUSE: UN PRESIDENTE DEFERENTE HACIA EL PRINCIPIO DEMOCRÁTICO}

El Congreso de los Estados Unidos no aprobó «el mandato individual» como impuesto, sino como una medida que se encontraba dentro de los poderes que la Constitución le otorga para regular el comercio interestatal ${ }^{68}$. A pesar de ello, lo cierto es que entre los autores que defendían la constitucionalidad «del mandato individual», de forma residual y, en cierto modo, a la manera de una malla de seguridad por si fallaba el argumento de la Commerce Clause o la Necessary and Proper Clause, era común apelar a la su adecuación constitucional ${ }^{69}$ con base en el poder que la Constitución otorga al Congreso para establecer y recaudar tributos con los proveer al bienestar de los Estados Unidos ${ }^{70}$. Este mismo argumento fue utilizado por el Gobierno, quien pese a no considerar el «mandato indi-

«adecuación» de la normativa. Vid. National Federation of Independent Business v. Sibelius, 567 U. S. _, 33 (2012).

${ }^{67}$ Vid. RANDY E. BARNNETT, «The Original Meaning of the Necessary and Proper Clause, op. cit., pp. 190 y ss.

68 Patient Protection and Affordable Care Act Sec. 1500A (1) «...The individual responsibility requirement provided for in this section (in this subsection referred to as the "requirement") is commercial and economic in nature, and substantially affects interstate commerce...»

${ }^{69} \mathrm{La}$ Taxing and Spending Clause viene consagrada en el Art. 1, Sec. 8, Cl. 1. ${ }^{a}$ de la Constitución: «The Congress shall have Power To lay and collect Taxes, Duties, Imposts and Excises, to pay the Debts and provide for the common Defence and general Welfare of the United States; but all Duties, Imposts and Excises shall be uniform throughout the United States».

70 Vid. GILLIAN MEZTGER, «Defense of Constitutionality...»; ERWIN CHEMERINSKY, «A defense of the Individual...» op. cit., pp. 620 y ss; ANDREW KOPPELMAN, «Bad News for Mail Roberts...» op. cit., p. 2; DAVID ORENTLICHER, «Constitutional Challenges to the...» op. cit., pp. 25-26. 
vidual» como un impuesto, alegó que este mandato estaría amparado, en cualquier caso, bajo el poder del Congreso para establecer y recaudar impuestos. Es decir, que la norma en discusión, aquella que imponía bajo sanción, un «mandato individual» a los ciudadanos de adquirir un seguro médico, podía interpretarse como la definición de un hecho imponible — el no tener seguro- que el Congreso federal podía gravar fiscalmente. En definitiva, se le pedía a la Corte Suprema que atendiera a otro de los significados jurídicos posibles del individual mandate para, en su caso, salvar la constitucionalidad de la normativa.

La respuesta que la mayoría de los jueces de la Corte Suprema iban a dar esta demanda de adecuación constitucional es fácil de prever si tomamos en consideración las dos citas con la que el juez Roberts inicia la opinión de la Corte. La primera de ellas, del Juez Story en el caso Parsons, reza lo siguiente: «ninguna Corte debería, al menos que los términos de la ley lo hagan insoslayable, dar una interpretación a la misma que implique un violación, incluso no intencionada, de la Constitución» ${ }^{71}$. La segunda cita es un extracto del voto concurrente de Holmes en Blodgett v. Holden, en el que se afirma que «entre dos posibles interpretaciones de una norma, en el caso de que una sea inconstitucional y la otra válida, nuestra obligación es adoptar aquella que salvará la norma» ${ }^{72}$. Es decir, que la Corte había de buscar una interpretación constitucionalmente conforme de la norma en cuestión, sin que sea necesario que esta sea la interpretación más natural o adecuada ${ }^{73}$, sino, simplemente, una de las interpretaciones «posibles» y «razonables» de la norma que quepa dentro la Constitución ${ }^{74}$.

Pues bien, para la mayoría de los jueces del Tribunal, esta lectura alternativa del «mandato individual» era razonable y posible. La forma en la que estaba diseñado el procedimiento recaudatorio del dinero que habían de pagar las personas que no contratasen el seguro, permitía, en opinión de la Corte, comprender prima facie, el mandato individual para adquirir un seguro, como el establecimiento de una condición con una determinada consecuencia fiscal que, en caso de incumplimiento, se debía de hacer efectiva a través de un pago adicional por parte del ciudadano en el momento en que este ingresase sus impuestos. No obstante, no toda consecuencia fiscal vinculada a un determinado comportamiento podía considerarse un legítimo ejercicio de las competencias del Congreso en materia tributaria. En concreto, no podríamos hablar de un ejercicio legítimo de estas competencias, cuando pudiera deducirse que las consecuencias fiscales

71 Parsons v. Bedford, 3 Pet. 433, 448-449 (1830).

72 Blodgett v. Holden, 275 U. S. 142, 148 (1927).

73 Crowel c. Benson, 285 U. S. 22, 62 (1932).

74 «Every reasonable construction must be resorted to, in order to save a statute from constitutionality» Hopper v. California, 155, U. S. 648, 657 (1985). 
impuestas tienen en realidad un carácter eminentemente sancionador. La difusa línea que separa la sanción del impuesto determinaba, en este caso, la legitimidad constitucional de la normativa.

Para confirmar la constitucionalidad del individual mandate como medida fiscal, la Corte lo contrasta con el precedente establecido con ocasión de la legislación sobre Child Labor Tax, una reforma fiscal que nació con el objeto de desincentivar el trabajo infantil y que finalmente fue declarada inconstitucional por su carácter sancionador ${ }^{75}$. Esta sentencia estableció tres criterios en virtud de los cuales puede determinarse el verdadero carácter sancionador de una tasa. En primer lugar, no podrán considerarse como tasas aquellas consecuencias jurídicas a un determinado comportamiento que impongan una carga excesiva. Tampoco, en segundo lugar, cuando la aplicación de la norma requiera constatar la conducta dolosa del ciudadano. Finalmente, no estaremos ante una tasa cuando el organismo recaudador no pertenezca a la administración tributaria del Gobierno Federal. Para la mayoría de la Corte, ninguna de las circunstancias señaladas se daba en esta ocasión. La normativa no imponía una carga excesiva al ciudadano que decidiese no contratar un seguro. La prueba más evidente de ello era, según la Corte, que podía demostrarse que en ningún caso el dinero que el ciudadano debía de pagar por no tener seguro iba a ser igual a lo que este hubiera tenido que pagar por contratar el seguro. Con lo cual, los ciudadanos sanos y jóvenes podían asumir libremente el riesgo de la decisión financiera de ahorrarse el dinero del seguro médico y pagar el impuesto correspondiente. Por otro lado, la ley no preveía la necesidad de probar ningún elemento intencional o doloso como condición para poder exigir el ingreso de la tasa, limitándose a eximir del pago a aquellas personas que no alcanzasen un nivel determinado de renta. Y, finalmente, este pago se recaudaba, no a través de ningún órgano ad hoc, sino a través de los mecanismo habituales de recaudación.

Pese a que parecía claro que el individual mandate podía subsumirse dentro del concepto de impuesto que había desarrollado la Corte en su jurisprudencia $\mathrm{y}$, por lo tanto, podía beneficiarse de una interpretación constitucionalmente conforme, la sentencia aún tenía que hacer frente a una cuestión de fondo fundamental, que era la de explicar por qué aquello que no puede hacerse en base a los poderes que la Commerce Clause confiere al Congreso, sancionar la inactividad económica, sí puede hacerse a través del poder de imponer tributos. Pues bien, para la mayoría de los jueces el poder tributario que la Constitución confiere al Congreso no es en ningún caso asimilable a aquél en base al cual puede regular

75 Bailey v. Drexel Furniture Co., 259 U. S. 20 (1922). 
el comercio interestatal. En este sentido, en primer lugar, si bien es claro que los poderes que la Constitución otorga al Congreso a través de la Commerce Clause presuponen una actividad económica existente que regular, no existe, en cambio, ningún compromiso constitucional a la hora de garantizar que el poder de imponer tributos recaiga sobre actividades económicas, de tal forma que sí es constitucionalmente posible gravar no sancionar la inactividad. Acudiendo a la conocida afirmación de Franklin de que «solo la muerte y los impuesto son ciertos», la Corte recuerda que el poder impositivo del Gobierno Central puede responder a muy distintos fines, entre otros, como sería este caso, al de incentivar una determinada conducta, gravando la contraria ${ }^{76}$. Por otro lado, la Corte insiste en el carácter mucho más modesto de los poderes conferidos al Congreso por la Tax Power Clause, con respecto a la Commerce Clause. Así, en ejercicio de sus competencias tributarias, el Congreso puede legislar única y exclusivamente imponiendo tributos, sin que de este poder se derive ninguna legitimación para imponer cualquier otra medida ${ }^{77}$. Sin embargo, la Commerce Clause sí legitima al Congreso para regular el comercio interestatal a través de todo tipo de medidas, incluyendo medidas penales o incluso la privación de ciertos derechos civiles, de ahí la necesidad de acotar su ámbito material. La intensidad del poder Tributario es mucho más tenue y, a su vez, y como consecuencia de ello, su ámbito de proyección material mucho menos restringido.

\section{THE MEDICAID EXPANSION Y LOS LÍMITES DEL FEDERALISMO FISCAL}

Como se ha señalado, el objetivo final de la reforma sanitaria, que no es otro que el de extender de forma prácticamente universal la cobertura sanitaria en los

${ }^{76}$ Letter from Benjamin Franklin to M. Le Roy (Nov. 1789) «Our new Constitution is now established ... but in this world nothing can be said to be certain, except death and taxes».

77 Para los Representantes aprobar un impuesto sanitario para los ciudadanos sin seguro, implicaba asumir una difícil responsabilidad y un riesgo con su electorado que no quisieron asumir, y, por eso, «etiquetaron» las consecuencias de no cumplir con el mandato de adquirir un seguro como una sanción y no como un impuesto. Como hemos visto, ha sido la Corte quien, para salvar la constitucionalidad de la reforma, ha vuelto a cambiar las etiquetas para convertir lo que era un mandato bajo sanción en un impuesto. Todo ello se produce a través de una operación hermenéutica que, como bien señaló es Scalia en su voto disidente, no deja de plantear un importante problema de naturaleza democrática ya que «imponer un impuesto a través del proceso judicial invierte el esquema constitucional y sitúa el poder tributario en aquél de los poderes del Estado que es menos responsable ante la ciudadanía». Tax and Spending Clause. Vid. Scalia (Dissenting) National Federation of Independent Business v. Sibelius, 567 U. S. _, 23-24 (2012). 
Estados Unidos, se sostenía sobre dos piedras angulares, el mandato individual para la adquisición de un seguro en el mercado privado, y la extensión del ámbito de beneficiarios del programa Federal Medicaid. En realidad, es esta extensión del Medicaid la que permite hablar realmente de la reforma sanitaria como una reforma que avanza en el paradigma social del Estado. $\mathrm{Y}$ es que su puesta en funcionamiento implica un incremento sustancial del gasto público hasta ahora destinado a garantizar la cobertura sanitaria de los ciudadanos americanos. A parte de los programas para personas que padeciesen ciertas discapacidades el Medicaid era un programa destinado principalmente a las familias sin recursos, si bien la legislación federal dejaba un margen especialmente generoso a los Estados para concretizar a partir de qué nivel de renta una familia podía participar del mismo, siempre relacionando esta cifra con el nivel familiar de ingresos a partir del cual se establecía el umbral federal de la pobreza ${ }^{78}$. Pues bien, el cambio introducido por la ACA es en este sentido más que sustancial ya que la reforma exige que el ámbito de beneficiarios sea extendido por los Estados, ya no a las familias, sino a todos los individuos menores de 65 años cuya cifra anual de ingresos no supere el $138 \%$ del nivel federal de la pobreza ${ }^{79}$. Al mismo tiempo que extiende este ámbito de beneficiarios, la reforma sanitaria amplia también lo que se conocía como el Essential Health Beneficiates, es decir, aquellas prestaciones sanitarias que necesariamente deben de estar cubiertas por el seguro médico que contraten los ciudadanos comprendidos dentro del ámbito de beneficiarios antes señalado. Estas modificaciones en el programa Medicaid implican, obviamente, un incremento sustancial del gasto público destinado a facilitar el acceso de los ciudadanos al tratamiento médico. Concretamente, el Congreso había estimado que para extender el Medicaid va a ser necesario un incremento de unos cien mil millones de dólares, con respecto al gasto actual. Incremento que hasta 2016 será

${ }^{78}$ Vid. En este sentido, hay que señalar que había gran disparidad entre los estados, aunque los diversos estudios económicos elaborados de forma previa a la reforma sanitaria habían concluido que en el caso de familias con los padres desempleados, el promedio federal era que dichas ayudas eran ofrecidas cuando la renta familiar no alcanzaba el $37 \%$ del nivel federal de la pobreza $\mathrm{y}$, en el caso de que alguno de los padres trabajase, este porcentaje se elevaba hasta el 63\% Vid. Kaiser Commission on Medicaid and the Uninsured, An Overview of Changes in the Federal Medical Assistance Percentages (FMAP) for Medicaid (July, 2011) Disponible en http://www.kff.org/medicaid/8210.cfm

79 Patient Protection and Affordable Care Act, Sec. 2001(a)(1) Para profundizar en los criterios y en los sistemas de cómputo establecidos por la ley, puede verse en extenso: Family Foundation, Explaining Health Reform: Benefits and Cost-Sharing for Adult Medicaid Beneficiaries (Aug. 2010), Disponible en http://www.kff.org/healthreform/8092.cfm 
asumido en su totalidad por Gobierno federal ${ }^{80}$, y a partir de ahí, el $10 \%$ del gasto total por la extensión del programa tendrá que ser asumido por los Estados. El Congreso defendía su autoridad para esta extensión del programa Medicaid en base a la Spending Clause de la Constitución, que otorga al Congreso el poder «to pay the Debts and provide for the common defence and general Welfare of the United States...». En gran medida, en este poder conferido al Estado por la Spending Clause ha constituido junto con la Commerce Clause el fundamento constitucional del federalismo cooperativo en los Estados Unidos. En base al mismo, el Gobierno Federal tiene un poder de gasto para realizar determinadas políticas públicas que promuevan el bienestar de la nación, las cuales, en la mayoría de los casos, van a requerir para su perfeccionamiento y ejecución del concurso de los Estados, ya que exigen medidas que no se encuentran dentro de los poderes conferidos al Gobierno Federal por la Constitución. Tanto en el New Deal, como especialmente durante el mandato del Lyndon Johnson, a través del Spending Clause se definieron los perfiles de lo que se vino a denominar el «federalismo creativo» ${ }^{81}$, que se basaba en el diseño federal de determinados programas de gasto público, en los que se condicionaban las transferencias financieras a los estados a la adopción por estos de determinas políticas consideradas por el Congreso como necesarias para promover el bienestar de toda la Nación. Lo que comúnmente se conoce como grant in aid. Ahora bien, en ningún caso, tal y como ha sido reiterado por la jurisprudencia de la Corte Suprema, esta "persuasión financiera» del Gobierno Central podría cruzar la línea a partir de la cual el incentivo fiscal deja de ser tal y se transforma en un instrumento de coacción hacia los Estados, que difumina la división entre las esferas de gobierno local y nacional establecida por la Constitución $^{82}$. Las políticas públicas del Gobierno Federal en base a la Spending Clause descansan, en este sentido, sobre la premisa de la existencia de un acuerdo de voluntades, es decir, de que «cuando el Estado acepta lo hace voluntariamente y consciente de los términos del contrato».

Establecer un criterio para diferenciar, desde un punto de vista constitucional, la legítima persuasión federal de la coacción no es algo fácil, y va a exigir en todos los casos, una lectura casuística de la naturaleza de las condi-

${ }^{80}$ Hasta ahora, el programa Medicaid estaba cofinanciado por el Gobierno Federal y los Estados. En concreto, la financiación federal oscilaba entre el $50 \%$ y el $74.18 \%$ todo ello en función de la renta per cápita de los Estados.

${ }^{81}$ Para un relato de estas políticas véase el capítulo dedicado al federalismo fiscal americano en MANUEL MEDINA GUERRERO, La incidencia del sistema de financiación en el ejercicio de las competencias de las comunidades autónomas, Madrid, 1993, pp. 97 y ss.

${ }^{82}$ La Corte se apoya a este respecto en la doctrina anticomandering establecida en New York $v$. United States, 505 U. S. 144 (1992). 
ciones impuestas por el Gobierno Central a los Estados. No obstante esta dificultad, de la jurisprudencia de la Corte Suprema sí es discernible un importante criterio orientativo y este es que no podrá considerarse que el Congreso actúa legítimamente bajo el poder de la Spending Clause cuando no deje en la práctica un margen de elección a los Estados para aceptar participar en un determinado programa federal, o bien, cuando las consecuencias de tal negativa sean excesivamente gravosas en términos financieros. Pues bien, a la luz de estos criterios, la mayoría de los jueces de la Corte consideraron que la expansión del programa Medicaid no podía estar amparada por los poderes conferidos por la Spending Clause al Congreso y, por lo tanto, que la reforma legislativa vulneraba en este punto el reparto de competencias entre el poder central y los Estados establecido por la Constitución. El fundamento de esta decisión gira en torno a las gravosas consecuencias que deberían soportar los estados que rehusaran aceptar las modificaciones sustanciales que se habían introducido en el Medicaid ${ }^{83}$. Y es que tal rechazo no solo conllevaría quedarse al margen de las nuevas partidas presupuestarias destinadas a financiar la extensión del programa, sino que suponía no poder participar en el programa ya existente ${ }^{84}$. Es decir, perder todos los fondos federales que hasta entonces recibían para la implementación de programas públicos de salud ${ }^{85}$. La exten-

${ }^{83} \mathrm{La}$ Corte insiste, en este sentido, en que la ley introducía de forma sobrevenida una modificación radical y con carácter retroactivo de las condiciones que fueron aceptadas por lo estados, sin dejar en la práctica ninguna posibilidad a estos para rechazarlas. Esta afirmación fue cuestionada en su voto particular por los Jueces Ginsburg y Sotomayor, quienes insisten en que, desde la aprobación del Medicaid en 1965, los Estados han tenido conocimiento de que el Gobierno Federal se reserva la posibilidad de modificar las condiciones del programa, y de hecho, el mismo ha sufrido más de 40 reformas desde su entrada en vigor. No obstante, como hemos visto, y como insiste la mayoría del Tribunal, en esta ocasión no se trataba de una reforma cualquiera sino que por la ampliación del ámbito de beneficiarios, se podía hablar más bien de una reformulación integral del programa. Vid. Ginsburg (Dissenting) National Federation of Independent Business $v$. Sibelius, 567 U. S. _, 58-59(2012).

${ }^{84}$ Antes de la reforma la participación en el programa Medicaid era opcional para los estados, si bien, todos ellos habían accedido a participar.

85 Para valorar el impacto económico que esta expulsión del Medicaid podía tener sobre los estados, la Corte toma en consideración que en la actualidad el gasto de los Estados en Medicaid supone, en la mayoría de los casos, en torno al 20\% de su presupuesto, y que el Gobierno Federal cubre entre el 50 y el $80 \%$ de esos costes. Por todo ello, podía estimarse que para muchos estados, rechazar la expansión del Medicaid aprobada por el Congreso significaba perder nada menos que una cantidad de financiación federal equivalente al $10 \%$ del presupuesto. Por este motivo, la Corte entiende que realmente la reforma sanitaria constituía un cambio radical y sobrevenido en el programa hasta entonces vigente, que dejaba en este extremo ninguna posibilidad de elección a los Estados National Federation of Independent Business v. Sibelius, 567 U. S. _, 54 (2012). 
sión del Medicaid a la que se instaba a los estados adolecía, en este sentido, de esa naturaleza contractual que ha de tener cualquier política pública federal de incentivos financieros para ser válida. Se trataría, en definitiva, de un programa coercitivo que no respeta la división territorial de esferas de gobierno establecida por la Constitución, al imponer en la práctica, y a través de los instrumentos del federalismo fiscal, una determinada política pública a los Estados en una materia donde ellos son competentes.

Contrastada la naturaleza coercitiva y, por lo tanto, la inconstitucionalidad de la extensión del Medicaid, la Corte debía de determinar el alcance de su decisión, para lo cual tenía dos opciones: decidir que únicamente sería inválida aquella parte del estatuto en la que se excluía del programa a los Estados que no aceptaran su extensión; o bien, declarar inválido el estatuto en su integridad. Pues bien, también en este caso la Corte va a mostrar de nuevo un importante grado de deferencia hacia el Congreso, y va a avalar la constitucionalidad del resto programa, dejando únicamente sin eficacia aquellas disposiciones que otorgaban la potestad sancionatoria a la Secretary of Health and Human Services ${ }^{86}$, para excluir del programa vigente a los Estados que se negasen a aceptar la ampliación. El fundamento de esta decisión se encontraría, en primer lugar, en que esta había sido la voluntad del Congreso, quien en la propia ley había dispuesto que si cualquier disposición relativa a la extensión del Medicaid era declarada inválida, el resto de provisiones debía de seguir siendo de aplicación ${ }^{87}$. Al mismo tiempo, la mayoría del Tribunal considera que con la nulidad de aquellas disposiciones que amenazaban a los estados con perder importantes ayudas financieras al no aceptar el nuevo programa, el conjunto de la reforma perdía todo carácter coercitivo ${ }^{88}$. Es decir, que los estados ahora podían libre-

${ }^{86}$ Desde el primer programa Medicaid, el Congreso había atribuido a la Secretary of Health and Human Services, la autoridad para controlar el cumplimiento por parte de los estados de las condiciones impuestas para la participación en el programa. En este sentido, el Medicaid otorgaba a este órgano la potestad sancionadora que se traducía en la práctica en la posibilidad de cancelar determinadas transferencias financieras, hasta el cumplimiento por el Estado de las condiciones impuestas.

87 If any provision of this chapter or the application thereof to any person or circumstance is held invalid, the remainder of the chapter, and the application of such provision to other persons or circumstances shall not be affected thereby. Sec.1396.

${ }^{88}$ Frente a esto, los jueces Scalia, Kennedy, Thomas y Alito, quienes habían compartido la opinión del presidente del Tribunal, con respecto a la inconstitucionalidad del Medicaidl Expansion, suscriben un voto particular, redactado por Scalia, defendiendo que dada la función central que la expansión del Medicaid desempeña dentro de la reforma sanitaria, y el hecho mismo de que gran parte de las normas tengan como presupuesto su eficacia, toda la Affordable Care Act debía de ser 
mente decidir participar o no en el nuevo programa, asumiendo las responsabilidades que ello conlleva.

\section{TRES REFLEXIONES A MODO DE CONCLUSIÓN}

\section{a) La insoportable perseverancia de la objeción contramayoritaria a la justicia constitucional}

Después de conocerse el fallo del Tribunal sobre la constitucionalidad de la ACA, Ronald Dworkin publicaba un comentario a la sentencia en el que se adentraba a explicar las razones por las que el juez Roberts se había apartado en esta ocasión de la mayoría conservadora del Congreso, avalando la constitucionalidad del individual mandate, y con ello, de la reforma sanitaria ${ }^{89}$. Para Dworkin, no se trataba de ninguna enajenación transitoria ni tampoco de una claudicación pusilánime o de una repentina conversión al liberalismo del Presidente. El voto de Roberts, que decidía por 5-4 la mayoría a favor de la constitucionalidad de la ACA, respondía a un sabio pragmatismo y a un necesario instinto de conservación, y es que en la opinión pública norteamericana cada vez era más palpable la consolidación de la idea de que las decisiones judiciales por la mínima responden en realidad a criterios preferentemente políticos ${ }^{90}$. Por ello, en este contexto de progresiva deslegitimación y frente a determinados litigios como este, de innegable dimensión pública, empezaba a resultar no solo prudente sino cada vez más necesario, salvaguardar la decisión política contenida en la ley, y no aparecer frente a la opinión pública ejerciendo «la última palabra», con la indisimulable mácula de no ser un órgano electo por los ciudadanos. Para Dworkin, por lo tanto, el juez Roberts en este caso había hecho lo que debía, y esto era no comportarse simplemente como un Juez sino ante todo como un «hombre de estado», y así salvar a la Corte del despres-

invalida por el Tribunal. Vid. Scalia (Dissenting) National Federation of Independent Business $v$. Sibelius, 567 U. S. _, 47-49(2012).

89 RONALD DWORKIN, "Why Did Roberts Change His Mind?» The New York Review of Books, 9 july, 2012.

90 Por estos mismos motivos, los profesores Geoffrey R. Stone y Jane Dailey, apuntaron también, en el Huffingtonpost, el carácter simbólico del voto del presidente Roberts en este caso, que en su opinión, redime a la Corte de hundirse en la crisis de legitimidad que arrastra desde Bush v. Gore. GEOFFREY R. STONE \&JANE DAILEY, «Savaging Roberts: Conservatives Run Amok», HUFFINGTON POST (July 3, 2012, 7:59 PM), http://www.huffingtonpost.com/ geoffrey-r-stone/savaging-roberts-conserva_b_1647980.html 
tigio social e incluso de la deslegitimación, de una forma similar a como hizo el otro juez Roberts durante el New Deal ${ }^{91}$.

Creo que es fácil coincidir con esta lectura psicológica que hace Dworkin del voto del Presidente Roberts, pero lo cierto es que no deja de resultar paradójico que sea precisamente un autor con una visión hercúlea del poder judicial como es Dworkin, quien vehementemente reclame deferencia hacia el legislador como exponente de «la decencia política de una democracia madura» ${ }^{92}$. Probablemente, la explicación a esto la encontremos en el hecho de que para un autor liberal como Dworkin no es lo mismo cuando el judicial review se proyecta sobre una cuestión relacionada con la distribución territorial del poder, que cuando están en juego los derechos y libertades consagrados en The Bill of Rights, un ámbito, este último, donde, dada su significación moral, la labor de control del juez adquiere un significado propio, vinculada a la protección del individuo frente a las mayorías parlamentarias. Ahora bien, tampoco es extraño encontrarnos con autores que llevan a cabo una lectura contraria a la que acabamos de hacer y que, dado el carácter en principio más estrictamente jurídico del control de judicial en estos casos, ven en la garantía del political balance entre los Estados y el Gobierno Federal, uno de los ámbitos propios del judicial review, mientras que, precisamente por su innegable calado moral, ponen en cuestión la legitimación judicial para revisar la legislación sobre determinados aspectos conflictivos del ejercicio de los derechos y libertades. El enfrentado diálogo mantenido en las páginas de la Harvard Law Review, entre la profesora Karlam y el profesor Calabresi, a propósito de la sentencia sobre la reforma sanitaria, define muy bien, en este sentido, el desencuentro irreconciliable entre ambas visiones. Para Karlam, la supremacía de la Corte Suprema como intérprete de la Constitución ha de simultanearse con una visión amplia de los poderes conferidos al Congreso ${ }^{93}$. Esta habría sido, en su opinión, la pauta que definió la acertada práctica judicial de la Corte Warren, la cual, si bien reafirmó su autoridad a la hora de interpretar las exigencias materiales sobre los Estados derivadas de la Bill of Rights de la

91 Véase, sobre este paralelismo y en sentido muy critico, pude verse JOHN YOO, WALL STREET JOURNAL, June 30-July 1,2012, at A15, http://online.wsj.com/article/SB10001424 052702303561504577496520011395292.html y RICHARD A. EPSTEIN, «What Was Roberts Thinking?» en Defining Ideas, Hoover Institution Journal, Stanford University, disponible en http:// www.hoover.org/publications/defining-ideas/article/121426

92 Una vehemencia que ya había adelantado en su artículo anterior: RONALD DWORKIN, «Why the Health Care Challenge is Wrong», en The New York Review of Books, http://www. nybooks.com/blogs/nyrblog/2012/apr/02/why-health-care-challenge-is-wrong/

93 PAMELA S. KARLAM, «Foreword: Democracy and Disdain», 126 Harvard Law Review, 2012.

(C) UNED. Revista de Derecho Político 
Constitución, fue al mismo tiempo muy deferente con los poderes del Congreso a la hora de realizar los valores constitucionales ${ }^{94}$. Esta lectura del judicial review que hace Karlam tiene un fundamento clásico, y este es el de que las libertades de los ciudadanos y sus posibilidades reales de participación en el proceso político no pueden ser equiparables a los derechos de los Estados, los cuales, por otro lado, siempre van a ver representados su intereses durante los trabajos legislativos. Los Estados, en definitiva, no son minorías discretas e insulares durante los procesos democráticos, sino uno de los principales actores de la creación normativa a nivel federal ${ }^{95}$, y por ello, la garantía de que la legislación federal respete los intereses estatales, descansa en el propio procedimiento legislativo y no en los jueces.

Como señalábamos, Calabresi, un viejo crítico del activismo judicial, contestaba enérgicamente esta lectura que hace Karlam, partiendo para ello, de una acusación nada piadosa con la autora — y, por extensión, con todos que se sitúan en sus tesis- que es la de que no ha entendido realmente en qué consiste la objeción contramayoritaria ${ }^{96}$. Y es que, en su opinión, la problemática del control de constitucionalidad de la ley surge cuando el Tribunal niega la legitimidad de una determinada decisión democrática con carácter general, es decir, independientemente del nivel de gobierno en la que esta decisión se tome, de tal forma que, las aspiraciones democráticas de los ciudadanos únicamente podrán canalizarse de forma extraordinaria a través de la enmienda constitucional. Esto sería lo que ocurre, obviamente, cuando el control judicial de la ley se hace bajo The Bill of Rights. Sin embargo, cuando los jueces controlan la adecuación constitucional de la ley sobre la base de las normas sobre distribución territorial del poder establecidas por la Constitución, no están sancionando ningún límite a las mayorías parlamentarias, sino simplemente están indicando qué nivel de gobierno es el que puede implementar una determinada política en base al federalismo establecido por la Constitución. Para Calabresi, la Constitución americana dedica la gran mayoría de sus preceptos a establecer reglas sobre la distribución del poder ya sea entre los distintos brazos del Gobierno de la Nación o entre la Federación y los Estados, y la verdadera razón de ser del judicial review no sería

94 Vid. PAMELA S. KARLAM, «Foreword: Democracy...», op. cit., pp. 14-25.

95 A este respecto, la tesis de Karlam es deudora por igual, principalmente, de JOHN H. ELY, Democracy and Distrust. A theory of Judicial Review, 1980 y JESSE H. CHOPER, Judicial Review and the National Political Process, A Functional Reconsideration of the Role of the Supreme Court, Chicago, 1980.

96 Vid. STEVEN G. CALABRESI, «Democracy and Disdain. In response to Pamela S. Karlam», 126 Harvard Law Review, 2012, p. 14. 
otra que la de conservar este esquema con el que The Framers quisieron controlar el ejercicio del poder político ${ }^{97}$.

De los problemas que plantea el control de constitucionalidad de las leyes sobre derechos fundamentales da buena cuenta el ingente debate que desde hace décadas ocupa a la doctrina americana. Ahora bien, en mi opinión, la sentencia sobre la reforma sanitaria sirve también para poner de manifiesto la dificultad que existe para mantener una visión tan poco traumática del judicial review en el ámbito del federalismo como la que como vemos sostienen autores como Calabresi. En buena medida, este tipo de lecturas se apoyan en una idea tan persistente como discutible, como es la de que las normas que distribuyen el poder entre la Federación y los Estados operan como verdaderas reglas de derecho, a diferencia de otras normas por definición vagas o principialistas, como serían las que consagran los derechos del Bill of Rights. Creo, en este sentido, que la jurisprudencia analizada en torno a la Commerce Clause y al concepto de actividad económica o comercio interestatal, deja bastante claro que el lenguaje de estas cláusulas dista de situarse en la exactitud y claridad que poseen las reglas de derecho, aproximándose, por el contrario, a la de los «conceptos esencialmente controvertidos» de los que hablara Waldrom ${ }^{98}$. A este respecto, el sentido último de la jurisdicción constitucional en el ámbito del federalismo no es otro que la definición de las competencias y materias y esta tarea, más aún en un sistema que, pese a tener una constitución escrita, está marcado por la incidencia casuística propia del Common Law, va a estar siempre repleta de «casos difíciles», tal y como ya lo advirtiera el Juez Marshall en McCulloch v. Maryland ${ }^{99}$. Señalado esto, lo que sí parece cierto es que, si bien es posible teorizar un modelo donde desaparezca el control de la ley sobre la base de las disposiciones constitucionales que consagran derechos fundamentales, la garantía de las estructuras del federalismo requiere el control judicial de los principios constitucionales sobre los que descansan. Ahora bien, como demuestra la sentencia del Tribunal en NFIB $v$. Sebelius, es más que ingenuo pensar que este control no es susceptible de plantear problemas de innegable naturaleza democrática. La existencia de diferentes niveles de gobierno no significa que la federación no albergue una comunidad

97 Vid. STEVEN G. CALABRESI, «Democracy and Disdain...» op. cit., pp. 16-20.

98 JEREMY WALDRON, «Vagueness in Law and Language: Some Philosophical Issues», 82 California Law Review, 509, 1994, 526-540.

99 «The [federal] government is acknowledged by all to be one of enumerated powers. The principle, that it can exercise only the powers granted to it... is now universally admitted. But the question respecting the extent of the powers actually granted, is perpetually arising, and will probably continue to arise, as long as our system shall exist McCulloch v. Maryland, 4 Wheat, 316 (1819) 
política unitaria en la que los ciudadanos quieren ver reflejadas sus aspiraciones con respecto a la sociedad en la que viven. En este sentido, la conflictividad del juicio de la ley va estar relacionada con el pedigree democrático de un determinado proceso legislativo, independientemente del nivel de gobierno en el que este se haya desarrollado ${ }^{100}$. Por este motivo es difícil de rechazar la idea de que el juicio de la ley, a través de las normas de distribución de competencias requerirá también, en muchos casos, un importante grado de «candor» judicial ${ }^{101}$, sobre todo en ciertos contextos como el examinado donde, tras el lenguaje del federalismo, se esconde una controversia política sobre la forma en la que el legislador ha implementado o canalizado ciertas demandas sociales. En estos contextos, adquiere pleno sentido aquella máxima de autocontrol judicial que le confesara el Juez Holmes a Harold Laski: «si mis conciudadanos quieran irse al infierno yo les ayudaré. Ese es mi trabajo». Creo que el juez Roberts, con palabras distintas, que no esconden cierto «desdén» hacia el legislador, quiso expresar lo mismo con este párrafo que cierra su opinión en NFIB v. Sibelius:

«Los padres de la Constitución crearon un Gobierno Federal con poderes limitados, y asignaron a esta Corte el desempeño de garantizar esos límites. Esto es lo que la Corte ha hecho hoy. Pero la Corte no puede expresar ninguna opinión sobre las buenas razones de la ley. Bajo esta Constitución, ese juicio está reservado al pueblo» ${ }^{102}$.

\section{b) El lenguaje del federalismo y la retórica de los derechos}

Visto con un poco de perspectiva el debate sobre la reforma sanitaria, creo que no deja de ser desconcertante para un observador extranjero comprobar cómo, si bien la retórica de los derechos acapara el ámbito de la discusión parlamentaria e incluso académica ${ }^{103}$, luego esta se diluye en el terreno propio de la

100 En este sentido, como señala La Pergola no solo no pude obviarse que el carácter procesal del federalismo, sino que hay que considerar que es un proceso que se define democráticamente. Vid. ANTONIO LA PERGOLA, «El federalismo cooperativo. Entra en escena el New Deal», en Los nuevos senderos del Federalismo, Madrid, 1994, p. 290.

101 Vid. MARIAN AHUMADA RUIZ, «City of Boerne v. Flores: La importancia del "candor" judicial», Revista Española de Derecho Constitucional, n. ${ }^{\circ}$ 54, 1998, pp. 311 y ss.

102 National Federation of Independent Business v. Sibelius, 567 U. S. _, 59 (2012).

103 Vid. SIERRA POWELL, «Rights Rhetoric in American Politics: A Case Study of American Political Discourse», Western Political Science Association 2011 Annual Meeting Paper, April 6, 2001; disponible en http://papers.ssrn.com/sol3/papers.cfm?abstract_id=1766888. Y, en general, sobre esta omnipresencia del discurso de los derechos en los Estados Unidos, puede verse, en 
justicia constitucional, bajo las categorías y el lenguaje del federalismo, en una especie de juego que, en broma, podríamos llamar: «dime qué federalismo defiendes y te diré qué tipo de liberal eres». En este sentido, como hemos visto, si bien la idea de implementar y garantizar «el derecho a la salud», es la idea central que sirve de impulso político a la reforma sanitaria ${ }^{104}$ y la que articula su defensa parlamentaria ${ }^{105}$, luego su implementación no se vincula a la Enmienda $\mathrm{XIV}^{106}$, ni tampoco, lo que puede llamar más la atención, al poder que la Constitución otorga al Congreso para promover el «Bienestar General» de los Estados Unidos $^{107}$, sino que el fundamento constitucional originariamente invocado por el Congreso es, como se ha visto, el poder del Congreso para regular actividades que afecten al comercio interestatal. Pero si esto puede llamar la atención, más significativa aún creo que es la forma jurídica a través de la cual se fundamentan las objeciones libertarias a la obligación de mantener un seguro impuesta por Congreso. Unas objeciones que, como hemos visto, no se articulan a través de otros preceptos constitucionales que apelan de forma explícita a la garantía de la libertad como la Quinta o la Décima Enmienda. Como es sabido, la razón de ello radica en algo tan sencillo como que la Corte ha delimitado de forma tasada las facetas de la libertad que pueden tener cobertura constitucional, de tal forma que no es posible articular la defensa frente a cualquier obligación impuesta por los poderes públicos a través de la Due Process of Law. De igual forma, la Décima Enmienda de la Constitución de los Estados Unidos — que, como es conocido, establece que «los poderes que la Constitución no delega a los Estados Unidos ni prohíbe a los Estados, quedan reservados a los Estados respectivamente o al pueblo»— nunca ha servido como vehículo procesal para la defensa de las libertades, y, en términos generales, ha tenido escasa relevancia como parámetro de

extenso, el trabajo al que reiteradamente remite la autora MARY ANN GLENDON, Rights Talk: The Impoverishment of Political Discourse, New York, 1993.

104 Véanse, en este sentido, BEATRIX HOFFMAN, «Health Care Reform and Social Movements in the United States» American Journal of Public Health, January 2003, Vol 93, No. 1.

105 Vid. REBECCA E. ZIETLOW, «Democratic Constitucionalism...», op. cit., pp. 13981400 .

106 Vid. FRANK J. MICHELMAN «Welfare Rights in a Constitutional Democracy», 3 Washington University Law Quarterly, 3 Summer, 1979, pp. 650 y ss.

107 En este sentido, los profesores Cooter y Siegel han defendido la necesidad de dar un contenido sustantivo al significado constitucional de la Welfare Clause del artículo uno de la Constitución, evitando así que el Congreso haya de acudir a construcciones forzadas o incluso desvirtuadas de la Commerce Clause, a la hora de querer promover ciertas políticas sociales. Vid. ROBERT D. COOTER \& NEIL SIEGEL, "Collective Action Federalism: A General Theory of Article I Section 8», 63 Stanford Law Review 115, 2010, pp. 170-171. 
control de la constitucionalidad ${ }^{108}$. Por este motivo, la defensa frente a determinadas obligaciones se articula no a través del lenguaje de los derechos sino del federalismo, lo que implica, en la práctica, cuestionar que la regulación de una determinada materia se encuentre amparada por alguno de los poderes enumerados a favor del Congreso. Todo ello se hace invocando reiteradamente una idea que estaría en el origen del sistema y que es la de que «la libertad se protege estableciendo dos niveles de gobierno». Una premisa, en cualquier caso, muy matizada por el tiempo, ya que si uno toma en consideración la historia constitucional del país, podría decirse que la extensión de los derechos civiles y también de las principales políticas sociales, se ha hecho a través de políticas federales que en no pocas ocasiones, encontraban reticencia a nivel estatal. En este sentido, creo que si ha habido una relación de proporcionalidad, esta probablemente se haya dado entre el incremento del poder de decisión del Gobierno Federal y la mejora en el estatuto de libertades y derechos de los ciudadanos. Obviamente, con esto estoy trayendo a colación un dato empírico y no quiere decir que una interpretación amplia de los poderes del Congreso no pueda ser utilizada en un momento determinado para implementar políticas que podamos considerar regresivas en el ámbito de los derechos ${ }^{109}$. Lo que quiero decir es que se puede afirmar que, en la experiencia americana, el progresivo fortalecimiento del Gobierno Federal ha coincidido en muchas ocasiones con la consolidación del estatuto de libertades de los ciudadanos.

En cualquier caso, el hecho de que el lenguaje del federalismo se ponga, en casos como el que hemos visto, al servicio de la defensa de la autonomía individual, no puede ocultar las aporías de esta idea que vincula descentralización y libertad. En un supuesto como el de la reforma sanitaria, por lo menos desde mi punto de vista, es difícil de argumentar, en este sentido, por qué motivo la obligación de adquirir un mínimo de cobertura sanitaria, si es impuesta por el Gobierno Federal se convierte en el impuesto sobre el té y los ciudadanos en súbditos del Rey Jorge III, y en cambio, es plenamente respetuosa con la

${ }^{108}$ En este sentido, desde United States v. Darby, 312 U. S. 100, 124 (1941) la Corte Suprema dejó reducido a un declaración retórica el enunciado normativo de la Décima Enmienda. Con posterioridad a Darby solamente en dos casos, el Tribunal ha juzgado inconstitucional una ley bajo esta enmienda. Se trata de las sentencias New York v. United States, 505 U. S. 144 (1992) y Mack and Printz v. United States, 521 U. S. 898 (1997) donde la Corte invalida en ambos caso leyes federales que imponían directamente obligaciones a los funcionarios estatales.

109 Vid. ERNST A. YOUNG, «Liberals Rediscover Federalism in the Wake of the War of Terror», 69 Brooklyn Law Review, p. 1277. 
libertad, cuando lo hace en los mismos términos el Estado de Massachussets ${ }^{110}$. Es cierto, en este sentido, que muy probablemente haya «puros libertarios» para quienes, apoyados no en el federalismo de la Constitución sino en la Enmienda XIV, «el mandato individual» entraría en contradicción con la Constitución americana independientemente de que haya sido aprobado o no por el Congreso. Sin embargo, no deja de dar la impresión de que, en muchos casos, la devoción por las virtudes libertarias del federalismo americano tiene una geometría variable, todo ello en función de cuál es la política que se quiere aprobar a través del Congreso Federal ${ }^{111}$ y sin olvidar que tampoco es imposible que ante ciertas políticas, los tradicionales defensores de la autoridad del Congreso puedan redescubrir las bondades del federalismo ${ }^{112}$.

\section{c) Más retórica federalista: la «soberanía» de los Estados}

En algún párrafo de la sentencia la Corte Suprema alude a la «soberanía de los Estados» a la hora de fundamentar su decisión de invalidar la extensión del programa Federal del Medicaid ${ }^{113}$. Esta apelación al concepto de «soberanía de los Estados» no es ni mucho menos inédita en la jurisprudencia americana, pero lo cierto es que, a diferencia de otros supuestos, en este caso la Corte sí entendió que ha existido una injerencia federal en este ámbito donde el Estado es «soberano», algo que obliga a quien pretenda leer esta jurisprudencia desde fuera, a plantearse el significado constitucional de un concepto que resulta difícil de conciliar no sólo con la idea de soberanía popular sino también con la más que evidente evolución centrípeta que ha experimentado el ordenamiento americano. Hace unos años, Rubin y Feely ya advertían, en este sentido, que gran parte del sustento teórico que la Corte Suprema da al federalismo americano viene marcado por un cierto retoricismo. Ya hemos visto cómo este retoricismo se manifiesta en la reiterada vinculación entre federalismo y libertad, pero en ocasiones el discurso federalista va más allá y apela a esta suerte de protección de los derechos

110 Véase el epígrafe dedicado al tratamiento del concepto de «mandato individual» por los políticos republicanos en ARTHUR NUSSBAUM, «Can Congress Make you bay Health Insurance? The Affordable Care Act, National Health Care Reform, and the Constitutionality of the Individual Mandate», 50 Duquesne Law Review, Spring, 2012, p. 457-466.

111 Vid. EDWARD L. RUBIN \& MALCOLM FEELEY, «Federalism: Some Notes on a National Neurosis», 41 UCLA Law Review 903, April, 1994, p. 935.

112 Sobre este «oportunismo» son excelentes las páginas de ERNST A. YOUNG, «Liberals Rediscover...», pp. 1308 y ss.

113 Concretamente, la Corte afirma: «The States are separate and independent sovereigns» Federation of Independent Business v. Sibelius, 567 U. S. _, 49 (2012). 
de los estados como comunidades políticas que albergan un ethos nacional propio. La crítica de Rubin y Feely a estas tesis parece fácil de compartir y parte de que esta lectura del federalismo adolece de un distanciamiento total con la realidad, ya que, a diferencia de lo que ocurre en otros contextos, no se puede afirmar que el federalismo americano esté vinculado a la protección de la identidad cultural o nacional de los estados de la Federación. Es más que discutible, en este sentido, que por lo menos después de la Guerra Civil, exista una relación entre federalismo y comunitarismo en los Estados Unidos y, en cualquier caso, parece claro que las comunidades políticas estatales no rivalizan con el carácter nacional de la comunidad política federal ${ }^{114}$. No obstante, si no parece una interpretación válida vincular la expresión «soberanía de los Estados» a la protección de una suerte de ethos nacional, se podría pensar, y esta sería una interpretación algo más ortodoxa, que la idea de «soberanía de los estados» remite a las teorías sobre el sustrato o los residuos contractualistas del federalismo americano, en virtud de las cuales, los estados mantendrían ciertas parcelas de soberanía. La idea sería, en este sentido, que en el lenguaje de la Corte ha pervivido, aunque sea con carácter residual, una idea de soberanía de los Estados vinculada a su original consentimiento para integrar la Unión. Como es conocido, esta tesis fue rebatida por el profesor La Pergola finales de los sesenta a partir de una idea que creo que es hoy, si cabe, más válida ${ }^{115}$ y que es la de que, frente a otras experiencias de descentralización, el federalismo americano ha estado marcado por una evolución centrípeta que, al mismo tiempo, ha mantenido intacta buena parte de su imagen fundadora, lo cual no necesariamente significa aceptar que los estados mantienen unas parcelas de soberanía como principales actores del pacto constituyente.

En realidad, y para concluir, creo la interpretación que hace la Corte de la Spendig Clause en NFIB v. Sibelius, y, en concreto, su apelación a la soberanía de los Estados, se puede explicar en la práctica de una manera más formal y mucho menos grandilocuente. Al invalidar un precepto que sancionaba con una reducción dramática las transferencias federales a los Estados que no quisieran asumir un programa social federal, la Corte Suprema lo que ha hecho es poner de manifiesto uno de los límites estructurales del federalismo cooperativo americano, que es la inmunidad de los estados frente a la coerción federal, expresada, en este caso, en la libertad que estos tienen para no prestar su consentimiento a participar en

114 Vid. JAMES GARDNER, «Whose Constitution Is It?: Why Federalism and Constitution Positivism Don't mix», 46 William and Mary Law Review, 2005, pp. 1246; ROBERT A. SHAPIRO, «Contingency and Universalism in State Separation of Powers Discourse», 4 Roger Williams University Law Review, 1998, en especial, pp. 83-87.

115 ANTONIO LA PERGOLA, Residui «contractualisti» e strutturafederalenell'ordinamentodegliStatiUniti, Milano, 1969. 
algunas de las políticas diseñadas por el Gobierno Central. En este sentido, y a pesar de la retórica empleada, me parece mucho más fácil concluir que, más que la soberanía de los estados que componen la Unión, la Corte ha reafirmado un principio de no coerción que, en cierto modo, marca una de la líneas que separan un estado genuinamente federal como el norteamericano de uno unitario descentralizado.

Title:

The United States' Supreme Court and the Federalism of the Welfare State. With regard to the constitutionality of the Healthcare Reform.

\section{Summary:}

Introduction. The Healthcare Reform: the Supreme Court versus a legislative milestone. 1. The (economic) fundamentals of the reform. 2. The Commerce Clause and the «individual mandate»: 2.1 The Commerce Clause in the American federalizing process; 2.2 The (second) New Federalism. A potentially libertarian federalism; 2.3 The Commerce Clause and the concept of economic activity: 2.3.1 The preliminary fumus boni irure; 2.3.2 A libertarian decision: Congress cannot impose an economic activity; 2.3.3 The new interpretation of the Necessary and Proper Clause. 3. The individual mandate and the Taxing and Spending Clause: The president's deference toward the democratic principle. 4. The Medicaid Expansion and the limits of the cooperative federalism. 5. Three reflections in conclusion: a) The Unbearable perseverance of the countermajoritarian objection to judicial review; b) The language of federalism and the rights rhetoric; c) More federalist rhetoric: the «sovereignty» of the States.

\section{Resumen:}

El presente artículo estudia el debate doctrinal y judicial sobre la constitucionalidad de la reforma sanitaria aprobada por el Congreso de los Estados Unidos. Concretamente, tras exponer cuáles son los fundamentos de esta reforma, este trabajo se va a centrar en los nuevos perfiles del federalismo cooperativo americano que se deducen de la interpretación que hace la Corte Suprema en National Federation of Independent Business $v$. Sibelius, de tres cláusulas clave en la evolución del modelo de distribución territorial del poder en los Estados Unidos de América: la Commerce Clause, la Necessary and Proper Clause y la Spending and Taxing Clause. Este estudio también se aproximará al debate surgido en torno a cuál ha de ser el nivel de deferencia hacia el legislador por parte de los jueces, a la hora de aplicar las reglas del poder 
territorial en el juicio de constitucionalidad de determinadas leyes de especial significación democrática. Para finalizar, también se analizará, a la luz de las objeciones libertarias vertidas contra la reforma, cómo progresivamente las categorías del federalismo desplazan a las del Bill of Righs en la defensa de ciertas libertades económicas frente a determinados programas sociales federales.

\section{Abstract:}

This article studies the doctrinal and judicial debate on the constitutionality of the Health Care Reform passed by the U. S. Congress. After exposing the foundations of the reform, the article focuses on the new profiles of the American cooperative federalism that stem from the interpretation that the Supreme Court has done in the National Federation of Independent Business $v$. Sibelius of three key clauses for the evolution of the territorial distribution of powers in the U. S. A: the Commerce Clause, the Necessary and Proper Clause and the Spending and Taxing Clause. Furthermore, this article reflects on which should be the degree of deference of judges to the legislator when it comes to enforce the rules of territorial power in judging the constitutionality of laws with particular democratic relevance. In light of the libertarian criticism on the reform, the article ends with an analysis on how the categories of federalism are increasingly displacing the Bills of Rights in the defense of certain economic freedoms in front of federal social programs.

\section{Key Words:}

Federalism USA, Healthcare Reform, Commerce Clause, Spending and Taxing Clause, Countermajoritarian objection to the Judicial Review.

\section{Palabras Clave:}

Federalismo USA, Reforma Sanitaria, Federalismo Fiscal, Federalismo Cooperativo, Objeción Contramayoritaria a la justicia constitucional. 